\title{
Numerical Evaluation of Microflaps for On Blade Control of Noise and Vibration
}

\author{
Ashwani K. Padthe, Li Liu ${ }^{\dagger}$ and Peretz P. Friedmann ${ }^{\ddagger}$ \\ Department of Aerospace Engineering, The University of Michigan, Ann Arbor, MI, 48109, USA
}

Active Gurney flaps, or microflaps, are studied to determine their effectiveness in reducing noise and vibration in rotorcraft, as well as improving rotor performance. The effectiveness of the microflap is examined using a comprehensive rotorcraft simulation code. The aerodynamic properties of the microflap is modeled using a nonlinear CFD based reduced order aerodynamic model that takes into account unsteadiness, compressibility and time varying freestream effects. Active control studies employing microflaps are conducted on a hingeless rotor configuration resembling the MBB BO-105, and various spanwise configurations of the microflaps, including a single, a dual, and a segmented five-microflap configuration are evaluated. Results indicate that the microflap is capable of substantial reductions in blade vortex interaction (BVI) noise ranging from 3-6 dB. Vibration reduction ranging from $\mathbf{7 0 - 9 0 \%}$ is also demonstrated. The interaction of vibration and noise reduction is also examined, and it was found reduction in one objective is accompanied by an increase in the other, a trend also observed when using other active approaches. Finally, the microflap is considered for combined vibration reduction and performance enhancement at a high speed cruise flight condition. The results clearly indicate that the microflaps are very effective for both noise and vibration reduction in helicopters, and they may also have potential for rotor performance enhancement.

\section{Nomenclature}

$\begin{array}{ll}b & \text { Airfoil semi-chord }=c / 2 \\ c & \text { Airfoil chord } \\ c_{p} & \text { Pressure coefficient on the airfoil surface } \\ C_{T} & \text { Rotor thrust coefficient } \\ \mathbf{C}_{0}, \mathbf{C}_{1}, \ldots, \mathbf{C}_{n+1} & \text { Rational function coefficient matrices } \\ \mathrm{C}_{d} & \text { Total drag coefficient } \\ \mathrm{C}_{d f} & \text { Parasitic drag coefficient of the fuselage } \\ \mathrm{C}_{l} & \text { Lift coefficient } \\ \mathrm{C}_{m} & \text { Moment coefficient } \\ \mathrm{C}_{h m} & \text { Hinge moment coefficient } \\ \mathrm{C}_{W} & \text { Helicopter Weight coefficient } \\ D_{0}, D_{1} & \text { Generalized flap motions } \\ \mathbf{D}, \mathbf{E}, \mathbf{R} & \text { Matrices defined in the RFA model } \\ e & \text { Blade root offset from the center of rotation } \\ \mathbf{f} & \text { Generalized load vector } \\ F_{H X 4}, F_{H Y 4}, & \text { Nondimensional 4/rev hub shears } \\ \quad F_{H Z} & \text { Laplace transform of } \mathbf{f}(\bar{t}) U(\bar{t}) \\ \mathbf{G} & \text { Airfoil plunge coordinate } \\ h & \text { Generalized motion vector } \\ \mathbf{h} & { }^{*} \text { Ph.D. Candidate, Student Member AIAA. } \\ { }^{\dagger} \text { Postdoctoral Researcher, Senior Member AIAA. } \\ { }^{\ddagger} \text { François-Xavier } \\ \text { Bagnoud Professor, Fellow AIAA, AHS }\end{array}$




\begin{tabular}{|c|c|}
\hline $\mathbf{H}$ & Laplace transform of $\mathbf{h}(\bar{t})$ \\
\hline$k$ & Reduced frequency $=\omega b / U$ \\
\hline$L_{b}$ & Blade length \\
\hline$L_{c}$ & Spanwise dimension of blade segment with microflap \\
\hline$M$ & Mach number \\
\hline & Blade mass \\
\hline $\begin{array}{c}M_{H X 4}, M_{H Y 4}, \\
M_{H Z 4}\end{array}$ & Nondimensional $4 /$ rev hub moments \\
\hline$M_{H z 1}$ & Total yawing moment about the hub \\
\hline & Number of rotor blades \\
\hline $\begin{array}{c}N_{H 06}, N_{H 07}, \\
\quad \cdots, N_{H 17}\end{array}$ & $6^{\text {th }}-17^{\text {th }}$ harmonic components of BVI noise \\
\hline$n_{L}$ & Number of lag terms \\
\hline$P_{R}$ & Rotor power \\
\hline $\bar{p}$ & Nondim. surface pressure distribution \\
\hline Q & Aerodynamic transfer function matrix \\
\hline$\tilde{\mathbf{Q}}$ & Approximation of $\mathbf{Q}$ \\
\hline$R$ & Blade radius \\
\hline$s$ & Laplace variable \\
\hline $\bar{s}$ & Nondim. Laplace variable $=s b / U$ \\
\hline $\mathrm{T}$ & Transfer matrix \\
\hline$t$ & Time \\
\hline $\bar{t}$ & Reduced time $=\frac{1}{b} \int_{0}^{t} U(\tau) d \tau$ \\
\hline$U(t)$ & Freestream velocity, time-dependent \\
\hline $\mathbf{u}$ & Control input vector \\
\hline$v, \Delta v, \Delta v_{a}$ & $\begin{array}{l}\text { Components of the local velocity at any point on the surface of the airfoil due to thickness, } \\
\text { camber, and angle of attack, respectively }\end{array}$ \\
\hline$V$ & Freestream velocity for the airfoil \\
\hline$W_{0}, W_{1}$ & Generalized airfoil motions \\
\hline$W_{\alpha}$ & Relative weighting parameter \\
\hline$X_{A}$ & Offset between the aerodynamic center and the elastic axis \\
\hline$X_{F A}, Z_{F A}$ & Longitudinal and vertical offsets between rotor hub and helicopter aerodynamic center \\
\hline$X_{F C}, Z_{F C}$ & Longitudinal and vertical offsets between rotor hub and helicopter center of gravity \\
\hline$X_{I b}$ & Offset of the blade cross-sectional center of mass from the elastic axis \\
\hline $\mathbf{x}(t)$ & Aerodynamic state vector \\
\hline$x_{c}$ & Spanwise location of center of microflap segment \\
\hline $\mathbf{z}$ & Output vector \\
\hline$\alpha$ & Airfoil angle of attack \\
\hline$\alpha_{R}$ & Rotor shaft angle \\
\hline$\beta_{p}$ & Blade precone angle \\
\hline$\delta_{f}$ & Flap deflection \\
\hline$\delta_{N C}, \delta_{N S}$ & $\mathrm{~N} / \mathrm{rev}$ cosine and sine components of flap deflection \\
\hline$\gamma$ & Lock number \\
\hline$\gamma_{n}$ & Rational approximant poles \\
\hline$\mu$ & Helicopter advance ratio \\
\hline$\omega$ & Oscillation frequency \\
\hline $\bar{\omega}$ & Nondim. normal velocity distribution \\
\hline$\Omega$ & Rotor angular speed \\
\hline$\omega_{F}, \omega_{L}, \omega_{T}$ & Blade flap, lead-lag and torsional natural frequencies \\
\hline$\psi$ & Azimuth angle \\
\hline$\sigma$ & Rotor solidity \\
\hline$\theta_{\mathrm{tw}}$ & Built-in twist angle \\
\hline
\end{tabular}




\section{Introduction and Background}

The deployable Gurney flap called the microflap has received substantial amount of attention recently as a promising candidate for on-blade control in helicopter rotors as well as wind turbines. This active control device is derived from the Gurney flap, which is a small tab typically less than $5 \%$ c in chord and is attached normal to the airfoil pressure surface at the trailing edge as shown in Fig. 1, originally conceived by Dan Gurney to increase the downward force generated by the spoiler on the race car. It has been shown in experimental studies that the Gurney flap is capable of increasing the maximum lift coefficient of an airfoil by up to $30 \%{ }^{1-4}$ One of the earliest experimental studies on aerodynamics of a Gurney flap was conducted by Liebeck, ${ }^{1}$ who hypothesized that the Gurney flap caused the flow to turn around the trailing edge resulting in the formation of two counter-rotating vortices behind the flap, shown in Fig. 1. The turning of the flow shifts the trailing edge stagnation point to the bottom edge of the microflap thus changing the Kutta condition and increasing the effective camber of the airfoil. Subsequently the effectiveness of the Gurney flap has also been confirmed using computational fluid dynamics (CFD) simulations. ${ }^{3,5-7}$

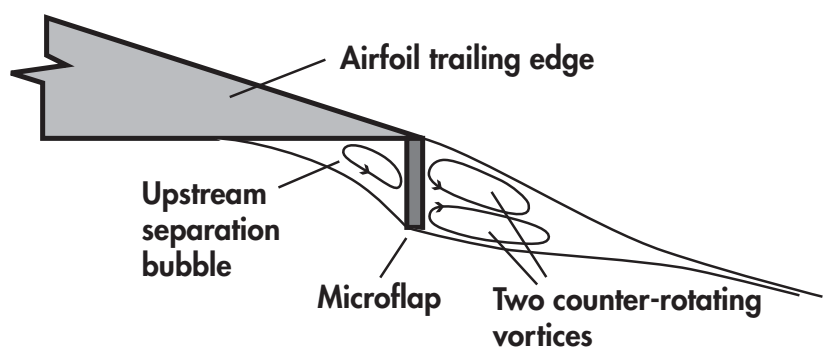

Figure 1. An illustration of the Gurney flap.

As an active control device, the microflap has the potential for high bandwidth control with low actuation power requirements, minimal loss in structural stiffness of the wing, and lower wing warping when compared to the conventional control surfaces, due to its small size and low inertia. The microflap has been studied for active control in several fixed wing applications such as flutter suppression of high aspect ratio flexible wings, ${ }^{8}$ aeroelastic control of a blended-wing-body configuration, ${ }^{9}$ and wing trailing edge vortex alleviation. ${ }^{10-12}$ It was found that the deployable microflaps can increase flutter speed of a highly flexible wing by up to $22 \%{ }^{8}$ Another study has proposed the use of microflap for control of aeroelastic response at the wing tip of a flexible blended-wing-body configuration. ${ }^{9}$ Recent studies ${ }^{10-12}$ also suggest that microflaps can be used for wake alleviation by inducing time-varying perturbations that excite vortex instability in the wake. The potential of microflaps with application to active load control in wind turbine blades was also explored computationally and experimentally on representative turbine airfoil sections. ${ }^{7,13}$ Substantial reduction in turbine blade root bending moment (reduction of peak bending moment ranging from 30-50\%) was observed in Ref. 14 using microflaps. Another appealing aspect of microflaps is that due to their small size they might be retrofitted on existing helicopter rotor blades with relatively few modifications.

During the last two decades, active rotor control using independent blade control (IBC) implemented through actively controlled partial span trailing edge flaps (ACF) has been shown to be effective for vibration and noise reduction in rotorcraft. ${ }^{15-20}$ It has also been employed for rotor performance enhancement through reduction of rotor power requirement. ${ }^{21,22} \mathrm{~A}$ computational study of the simultaneous vibration and noise reduction in rotorcraft using the ACF system was conducted in Ref. 18. A fully coupled aeroelastic and aeroacoustic simulation capability was developed and incorporated into the comprehensive rotorcraft simulation code AVINOR (Active VIbration and NOise Reduction). ${ }^{23}$ A modified version of the helicopter aeroacoustic code WOPWOP ${ }^{24}$ was used to calculate rotor noise under BVI conditions. This unified aeroelastic/aeroacoustic analysis code was also validated against experimental measurements and good correlation was demonstrated. Significant BVI noise reduction of 3-5dB was found, in conjunction with about $40 \%$ vibration reduction, using single and dual ACF configurations. In addition to computational studies, the effectiveness of the ACF system has been demonstrated by a few small scale wind tunnel tests and full scale tests. ${ }^{17,19,20,25}$ A multiple piezoelectrically actuated flap system has been successfully flight tested by Eurocopter in Germany. ${ }^{19}$ Another full scale test on a MD900 rotor equipped with a single piezoelectrically actuated flap has been carried out in the $40 \times 80 \mathrm{ft}$ wind tunnel at NASA Ames. ${ }^{20}$ These tests have demonstrated good vibration reduction capability $(60-80 \%)$ and good noise reduction capability (4-6 dB) under 
BVI conditions for the ACF systems.

Despite the demonstrated effectiveness of the ACF system, its practical implementation in a production military or civilian rotorcraft has not materialized. The principal reason has been the complexity and cost of the system that prevents one from retrofitting the system on an existing rotor. The advantages of the microflap in size and actuation power requirement when compared to the conventional ACFs make them a potentially attractive alternative for on-blade rotor control, and may facilitate retrofitting on existing rotor systems. Several computational and experimental studies have considered microflaps for rotorcraft performance enhancement. ${ }^{26-29}$ A relatively simple deployment schedule where the microflaps are deployed primarily on retreating side of the disk was used, and the maximum thrust of the rotor was enhanced by $10 \%$ using microflaps with a height of $1 \%$ c distributed along the entire blade span. A Navier-Stokes flow solver coupled with a structural dynamics solver was employed in Ref. 30 to study the effectiveness of microflap for rotor vibration reduction. The oscillating microflap was simulated using a dynamic wall boundary condition. The control inputs to the microflap were manually adjusted in magnitudes and phase angles in order to identify the optimal input for vibration reduction. More than $80 \%$ reduction in the vertical vibratory loads was found using this approach. In a series of recent studies, ${ }^{31-33}$ the microflap was employed in open and closed loop control for vibration reduction in rotorcraft. The unsteady aerodynamic effects of the microflap were modeled using a nonlinear reduced order model (ROM) constructed from CFD data obtained with a Navier-Stokes flow solver. Various spanwise configurations of the microflaps were considered, including a single, a dual, and a segmented five-microflap configuration. The results indicate that the microflap is very effective for vibration reduction in rotorcraft and it is capable of achieving substantial reductions in excess of $80 \%$.

The overall objective of this paper is to to conduct a comprehensive evaluation of the potential of the microflap for active control in rotorcraft, using numerical simulations. The main emphasis here is on vibration and noise reduction, and a limited consideration of performance enhancement with the microflap is also conducted, at forward flight conditions. The specific objectives are:

1. Validate the aerodynamic and acoustic computations from the comprehensive rotorcraft simulation code against experimental data;

2. Explore the potential of the microflap for active control of blade vortex interaction noise, for a low speed descending flight condition where BVI effects are dominant;

3. Investigate the mutual interactions of vibration and noise reduction using the microflap at the BVI condition;

4. Compare the microflap to a conventional trailing-edge plain flap in terms of its vibration and noise reduction capabilities;

5. Examine the potential of microflap for rotor performance enhancement at a high speed cruise condition.

\section{A CFD Based ROM for an Airfoil Equipped with Microflap}

The strong nonlinear nature of viscous flow behind the microflap implies that the effect of the microflap needs to be considered using a CFD based approach. Although various CFD tools have been used to determine the aerodynamic characteristics of a Gurney flap or microflap with reasonable accuracy, the computational costs of coupling CFD solvers directly with rotorcraft simulation codes are prohibitive when conducting parametric trend studies involving active control. A nonlinear CFD based reduced-order aerodynamic model developed in Ref. 31 has been shown to be accurate, efficient, and suitable for combination with comprehensive rotorcraft codes. Furthermore, this model can be used to represent the effects of various trailing edge control devices, including microflaps and conventional flaps. To develop the reduced-order model, a compressible unsteady Reynolds-Averaged Navier-Stokes CFD solver is used to generate frequency domain aerodynamic response, which is then converted to the time-domain using the Rational Function Approximation (RFA) approach.

The RFA approach has been used in the past to generate a Laplace transform or state variable representation of the unsteady aerodynamics of a wing section for fixed wing applications ${ }^{34-37}$ as well as rotary wing applications. ${ }^{38}$ The resulting reduced-order aerodynamic model is a state-space, time domain model that accounts for flow unsteadiness and compressibility. In Ref. 38 the RFA aerodynamic model was developed 
for modeling the aerodynamic response of a two-dimensional airfoil/trailing edge flap combination. Recently, the accuracy of this model was also verified by comparing its unsteady aerodynamic load predictions with CFD for a two-dimensional airfoil/oscillating flap combination over a wide range of aerodynamic conditions representative of rotorcraft applications. ${ }^{39,40}$

The new CFD based reduced order model developed using the RFA approach, referred to as the CFD+RFA model, has the same advantages as the original RFA model: 1) it allows a convenient combination of the aerodynamics with the structural dynamic model; 2) it facilitates the solution procedure of the combined system governed by equations with periodic coefficients, using numerical integration; and 3) it provides a degree of computational efficiency required by the implementation of active control techniques such as trailing edge flaps and microflaps. Therefore, the CFD+RFA model is ideally suited for use with comprehensive codes for aeroelastic simulations and active control studies.

\section{I.A. Concise description of the RFA approach}

The RFA approach used in conjunction with CFD to obtain the ROM is concisely described below. Additional details can be found in Ref. 31. The RFA model is based on Roger's approximation ${ }^{34}$ and represents a relation between generalized aerodynamic loads and generalized motions of the aerodynamic surface in Laplace domain as

$$
\mathbf{G}(\bar{s})=\mathbf{Q}(\bar{s}) \mathbf{H}(\bar{s})
$$

where $\mathbf{G}(\bar{s})$ and $\mathbf{H}(\bar{s})$ are the Laplace transforms of the column matrices representing generalized aerodynamic load and generalized motion, respectively. The aerodynamic transfer matrix $\mathbf{Q}(\bar{s})$ is approximated using the Least Squares approach with a rational expression of the form

$$
\tilde{\mathbf{Q}}(\bar{s})=\mathbf{C}_{0}+\mathbf{C}_{1} \bar{s}+\sum_{n=1}^{n_{L}} \frac{\bar{s}}{\bar{s}+\gamma_{n}} \mathbf{C}_{n+1}
$$

The poles $\gamma_{1}, \gamma_{2}, \ldots, \gamma_{n_{L}}$ are assumed to be positive valued to produce stable open loop roots. Arbitrary motions of the airfoil and a conventional trailing edge flap are represented by four generalized motions shown in Fig. 2. The normal velocity distributions shown in Fig. 2 correspond to two generalized airfoil motions (denoted by $\mathrm{W}_{0}$ and $\mathrm{W}_{1}$ ) and two generalized flap motions (denoted by $\mathrm{D}_{0}$ and $\mathrm{D}_{1}$ ). The two generalized flap motions represent the angular deflection of a conventional trailing edge flap.

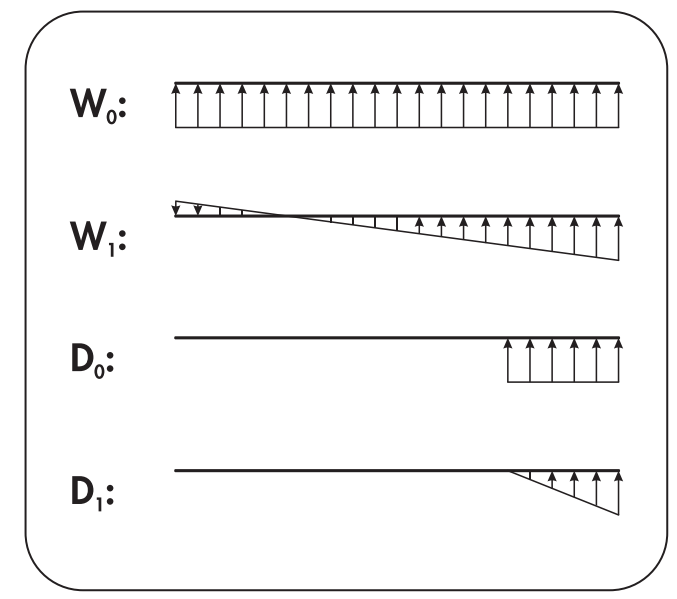

Figure 2. Normal velocity distribution corresponding to generalized airfoil and plain flap motions.

When constructing the RFA model for an airfoil with microflap, two generalized airfoil motions represented by $W_{0}$ and $W_{1}$, shown in Fig. 2, are used to describe arbitrary airfoil pitch and plunge motion. In terms of classical pitch and plunge coordinates $\alpha$ and $h$, these generalized motions are expressed as

$$
\begin{aligned}
& W_{0}=U \alpha+\dot{h}, \\
& W_{1}=b \dot{\alpha} .
\end{aligned}
$$


Thus, the description of the airfoil motion is identical to that used in the original RFA model. For the microflap, the concept of normal velocity distributions is no longer meaningful; therefore, the microflap is simply characterized by one generalized motion, namely, the deflection $\delta_{f}$, where the deflection represents the deployment amplitude, or the angular deflection, depending on the microflap configuration. The generalized motion $D_{1}$, used in the original RFA model to describe the motion of conventional flaps, is no longer used. This is justified because the generalized motion $D_{1}$ primarily represents the apparent mass effect, which is found to be insignificant for the microflap in the CFD simulations. Therefore, the generalized motion vector $\mathbf{h}$ for the microflap is expressed as

$$
\mathbf{h}=\left\{\begin{array}{c}
W_{0} \\
W_{1} \\
D_{0}
\end{array}\right\}
$$

where,

$$
D_{0}=\delta_{f}
$$

In order to find $\tilde{\mathbf{Q}}(\bar{s})$, tabulated oscillatory airloads, i.e. sectional lift, moment and hinge moment, need to be obtained corresponding to the generalized motions. In the original RFA implementation, the oscillatory airloads in the frequency domain were obtained from a potential flow solver which provides a two-dimensional doublet lattice (DL) solution of Possio's integral equation. ${ }^{38}$ This approach was found to be very efficient for generating a set of aerodynamic response data for the generalized motions of airfoil/flap combination. The frequency domain information is generated for an appropriate set of reduced frequencies and Mach numbers, encompassing the entire range of unsteady flow conditions encountered in practical applications.

To construct a CFD based RFA model, a commercially available CFD solver CFD $++{ }^{41,42}$ developed by METACOMP Technologies was used to generate the frequency domain responses. This results in a ROM that captures the strong viscous flow behind a microflap, and also provides unsteady drag predictions which cannot be obtained from potential flow theory. Furthermore, significant flow nonlinearities associated with viscous effects or shock wave formation are also accounted for in this approach.

A state space representation of the RFA aerodynamic model is derived by defining a generalized motion vector $\mathbf{h}$ and a generalized load vector $\mathbf{f}$, as:

$$
\begin{aligned}
& \mathbf{h}=\left\{\begin{array}{l}
W_{0} \\
W_{1} \\
D_{0} \\
D_{1}
\end{array}\right\} \quad \text { for plain flap, or } \\
& \mathbf{h}=\left\{\begin{array}{l}
W_{0} \\
W_{1} \\
\delta_{f}
\end{array}\right\} \text { for microflap, }
\end{aligned}
$$

and

$$
\mathbf{f}=\left\{\begin{array}{c}
\mathrm{C}_{l} \\
\mathrm{C}_{m} \\
\mathrm{C}_{d} \\
\mathrm{C}_{h m}
\end{array}\right\}
$$

Note that hinge moment $\mathrm{C}_{h m}$ is applicable only for conventional flaps and is not needed for microflaps. The rational approximant $\tilde{\mathbf{Q}}$ in Eq. (2) can be transformed to the time domain using the inverse Laplace transform, which yields the final form of the state space model, given below

$$
\begin{aligned}
\dot{\mathbf{x}}(t) & =\frac{U(t)}{b} \mathbf{R}\left(M, \alpha, \delta_{f}\right) \mathbf{x}(t)+\mathbf{E}\left(M, \alpha, \delta_{f}\right) \dot{\mathbf{h}}(t), \\
\mathbf{f}(t) & =\frac{1}{U(t)}\left[\mathbf{C}_{0}\left(M, \alpha, \delta_{f}\right) \mathbf{h}(t)\right. \\
& \left.+\mathbf{C}_{1}\left(M, \alpha, \delta_{f}\right) \frac{b}{U(t)} \dot{\mathbf{h}}(t)+\mathbf{D} \mathbf{x}(t)\right]
\end{aligned}
$$


where the definitions of matrices $\mathbf{D}, \mathbf{R}$ and $\mathbf{E}$ can be found in Ref. 38 .

Note that in order to account for flow nonlinearities encountered at high Mach numbers, large angles of attack and flap deflections, the RFA model has been enhanced by using a technique referred to as model scheduling, ${ }^{43}$ wherein different sets of RFA coefficients are generated at appropriate combinations of the Mach number, angle of attack, and flap deflection angle. Specifically, the RFA model is modified by allowing the coefficient matrices, i.e., $\mathbf{R}, \mathbf{E}, \mathbf{C}_{0}, \mathbf{C}_{1}, \ldots$, to vary with $M, \alpha$, and $\delta_{f}$, as indicated in Eq. (10).

\section{I.B. CFD simulations}

As stated earlier, the CFD results for constructing the ROM are obtained using the CFD ++ code, which is capable of solving the compressible unsteady Reynolds-Averaged Navier-Stokes equations. It uses a unified grid methodology that can handle a variety of structured, unstructured, multi-block meshes and cell types, including patched and overset grid features. Spatial discretization is based on a second order multidimensional Total Variation Diminishing (TVD) scheme. For temporal scheme an implicit algorithm with dual time-stepping is employed to perform time-dependent flow simulations, with multigrid convergence acceleration. Various turbulence models are available in $\mathrm{CFD}++$ and the Spalart-Allmaras model is used for the current study, assuming fully turbulent boundary layer.

In Ref. 44 three candidate microflap configurations, shown in Fig. 3, were examined and compared for their effectiveness in generating unsteady airloads. The sharp trailing edge configuration (Fig. 3a) was determined to be the best compromise between the aerodynamic benefits and the ease of implementation in rotor blades; therefore it is chosen for the current study. The CFD grids employed for this configuration are shown in Fig. 4(b); grids for a $20 \%$ plain flap are also shown in Fig. 4(c). The overall computational domain is shown in Fig. 4(a) which contains approximately 90,000 grid points. The CFD grids for the various microflap or plain flap configurations are generated using the overset approach, which is a convenient method for modeling complex geometries and moving components with large relative motions. The grids are clustered at the airfoil wall boundaries such that the dimensionless distance $y^{+}$of the first grid point off the wall is less than 1 and the equations are solved directly to the walls without assuming wall functions.

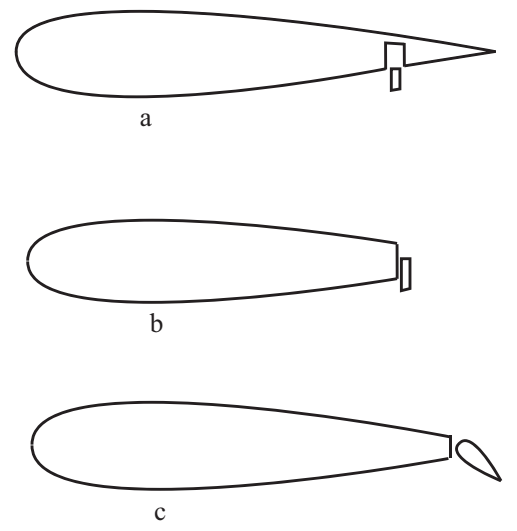

Figure 3. Various microflap configurations.

In order to generate a $\mathrm{ROM}$ that can represent the entire range of flow conditions encountered by the blades at various advance ratios, CFD simulations are conducted for Mach numbers ranging from 0.05 to 0.9 and angles of attack ranging from $0^{\circ}$ to $15^{\circ}$. All the simulations were carried out for the NACA0012 airfoil at Reynolds number $2.1 \times 10^{6}$. At each flow condition defined by the free stream Mach number and the airfoil mean angle of attack, simulations are performed to generate frequency domain data corresponding to the generalized motions at reduced frequency values ranging from 0.02 to 0.2 with an increment of 0.02 . Note that the $5 / \mathrm{rev}$ frequency at $0.75 \mathrm{R}$ span location on the rotor blade of a representative MBB BO-105 rotor configuration corresponds to a reduced frequency of 0.18 . The frequency domain data obtained through CFD simulations is subsequently used to generate the coefficients $\mathrm{C}_{0}, \mathrm{C}_{1}, \ldots, \mathrm{C}_{n}$ in the CFD+RFA reduced order model. These coefficients are generated from CFD results at simulated flow conditions and then a "shape-preserving" piecewise cubic Hermite polynomial interpolation scheme ${ }^{45-47}$ is used to evaluate the coefficients at intermediate flow conditions. In this interpolation scheme, the slopes of the interpolating function at the data points are determined such that the function evaluations do not significantly overshoot 


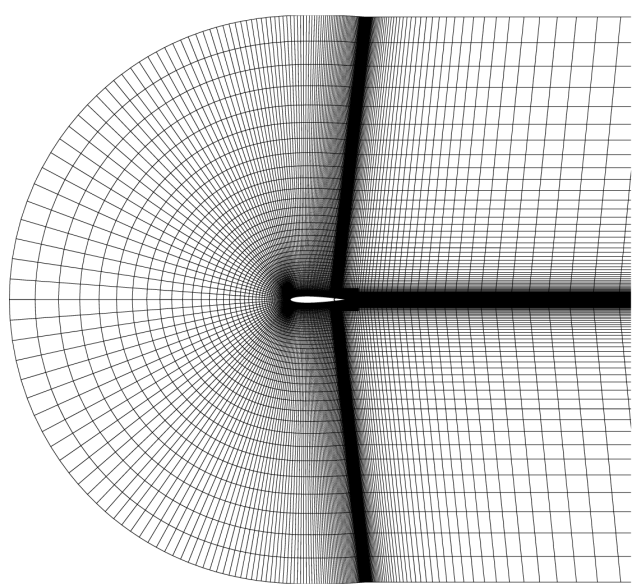

(a) Grid overview

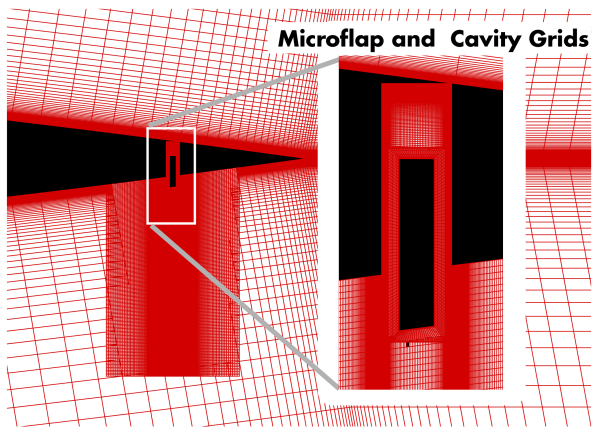

(b) Close-up grid for microflap

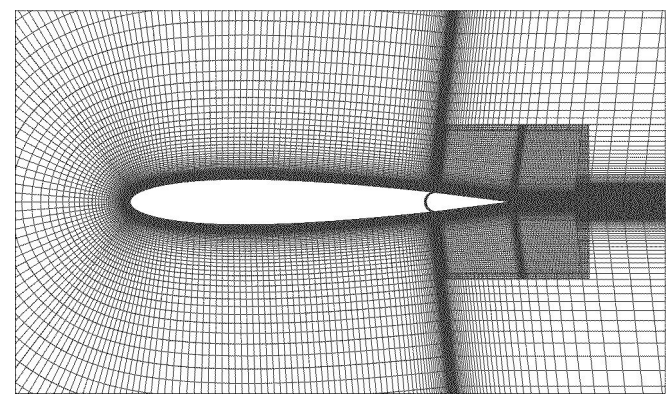

(c) Close-up grid for plain flap

Figure 4. Grids used for CFD simulations.

the fitting data values. Complete validations of the CFD+RFA model by comparing the ROM predictions to direct CFD simulations can be found in Refs. 44 and 48, for a wide range of flow conditions and unsteady microflap/plain flap deflections.

\section{Description of the Rotorcraft Aeroelastic Analysis Code}

Active vibration reduction studies with the microflap are conducted using a comprehensive rotorcraft aeroelastic analysis code AVINOR which has been extensively validated. ${ }^{18,23,49}$ The CFD+RFA model described earlier has been incorporated into AVINOR and is used to model the effect of microflaps, as well as plain trailing edge flaps for comparison purposes. The ability to model segmented multiple microflap configurations has been incorporated into the code. The principal ingredients of the AVINOR code are concisely summarized in the following subsections.

\section{II.A. Aerodynamic model}

The blade/flap sectional aerodynamic loads for attached flow are calculated using the CFD+RFA model, that was described earlier. This model provides unsteady lift, moment, as well as drag predictions for both plain flap and microflap configurations. The RFA model for the blade-flap combination is linked to a free wake model described in Refs. 49 and 18, which produces a spanwise and azimuthally varying inflow distribution. For separated flow regime, the aerodynamic loads are calculated using the ONERA dynamic stall model.

\section{II.B. Structural dynamic model}

The structural dynamic model used for the present study consists of a four-bladed hingeless rotor, with fully coupled flap-lag-torsional dynamics with moderate deflections. The structural equations of motion are discretized using the global Galerkin method, based upon the free vibration modes of the rotating blade. 
The dynamics of the blade are represented by three flap, two lead-lag, and two torsional modes. Each free vibration mode was calculated using the first nine exact non-rotating modes of a uniform cantilevered beam. The effect of control surfaces such as the trailing-edge plain flap or the microflap on the structural properties of the blade is assumed to be negligible. The control surfaces influence the behavior of the blade only through their effect on the aerodynamic and inertial loads.

\section{II.C. Coupled aeroelastic response/trim solution}

The combined structural and aerodynamic equations form a system of coupled differential equations that can be cast in state-variable form. The trim procedure used is based on a propulsive trim with three force equations (longitudinal, lateral, and vertical) and three moment equations (roll, pitch, and yaw) corresponding to a helicopter in free flight. A simplified tail rotor model, based on uniform inflow and blade element theory, is used. The six trim variables are the rotor shaft angle $\alpha_{R}$, the collective pitch $\theta_{0}$, the cyclic pitch $\theta_{1 s}$ and $\theta_{1 c}$, the tail rotor constant pitch $\theta_{0 t}$, and lateral roll angle $\phi_{R}$. The coupled trim/aeroelastic equations are solved in time using the ODE solver DDEABM, which is a predictor-corrector based Adams-Bashforth differential system solver.

\section{II.D. Acoustic model}

The acoustic analysis is based on a modified version of the WOPWOP code, which computes helicopter noise using the Ffowcs-Williams Hawkings equation with the quadrupole term neglected. ${ }^{24}$ The version of WOPWOP used in the code was modified to account for a fully flexible blade model that is compatible with the structural dynamic model described earlier. In previous studies conducted in Refs. 50 and 18, the chordwise pressure distribution on the surface of the blade, required as input to the acoustic computations, is calculated using an extended RFA approach that produces the unsteady compressible chordwise and spanwise pressure distribution over the entire rotor disk. This extended RFA approach to obtain pressure distribution is based on pressure fitting data in the frequency domain generated from a DL based potential flow solver, described in detail in Ref. 50. In the present study, the pressure distribution cannot be obtained with the previous approach, because it is computationally expensive to generate RFA models using CFD based pressure distribution data. Therefore, the blade pressure distributions are estimated using the velocity superposition method, ${ }^{51}$ where the pressures are obtained from the sectional lift coefficients. Specifically, based on potential flow theory the pressure distribution on the surface of the airfoil is related to the local velocity distribution, which can be considered to be composed of three independent components

$$
c_{p}=\left(\frac{v}{V} \pm \frac{\Delta v}{V} \pm \frac{\Delta v_{a}}{V}\right)^{2}
$$

where the velocity ratios $\frac{v}{V}, \frac{\Delta v}{V}$, and $\frac{\Delta v_{a}}{V}$ represent the contributions due to airfoil thickness, camber, and angle of attack, respectively. The signs in Eq. 11 are positive for the upper surface and negative for the lower surface. For the symmetric NACA0012 airfoil used in the present study, $\frac{\Delta v}{V}=0$, and the values of the other two components can be found using the approach outlined in Ref. 51. Clearly this approach may introduce a significant source of error as it is based on potential flow theory; however, reasonable approximations may be obtained since the integrated lift coefficients, used to generate the pressure, are obtained with the CFD based model that accounts for compressibility and unsteady effects.

\section{Control Algorithm}

The Higher Harmonic Control (HHC) algorithm has been used in the past to successfully achieve vibration and noise reduction in rotorcraft. ${ }^{15,18} \mathrm{~A}$ detailed description of the algorithm, including robustness and stability analyses, can be found in Ref. 52 . The HHC algorithm is based on a linear, quasi-static, frequencydomain model of the helicopter response to control input. For a 4-bladed rotor, the control input $\mathbf{u}$ is a combination of the $2 / \mathrm{rev}, 3 / \mathrm{rev}, 4 / \mathrm{rev}$, and $5 / \mathrm{rev}$ harmonic components of the flap deflection. Note that the flap deflection referred to here in this section applies to both the microflap and the conventional trailing-edge 
flap. The total flap deflection is thus given by

$$
\delta_{f}(\psi)=\sum_{N=2}^{5}\left[\delta_{N c} \cos (N \psi)+\delta_{N s} \sin (N \psi)\right]
$$

For vibration reduction studies, the output vector $\mathbf{z}$ consists of $4 /$ rev vibratory hub shears and moments given by

$$
\mathbf{z}_{V R}=\left[\begin{array}{llllll}
F_{H X 4} & F_{H Y 4} & F_{H Z 4} & M_{H X 4} & M_{H Y 4} & M_{H Z 4}
\end{array}\right]^{T}
$$

For BVI noise reduction studies, the output vector $\mathbf{z}$ consists of the $6^{\text {th }}-17^{\text {th }}$ harmonic components of BVI noise, as measured at a microphone installed at a suitable location. This location is usually on the skid or landing gear of the helicopter, and

$$
\mathbf{z}_{N R}=\left[\begin{array}{lllll}
N_{H 06} & N_{H 07} & N_{H 08} & \cdots & N_{H 17}
\end{array}\right]^{T}
$$

Using active control for rotor performance enhancement requires another objective to be defined, which is the rotor power

$$
\mathbf{z}_{P R}=\left[P_{R}\right]
$$

where $P_{R}$ denotes the average rotor shaft power. The average rotor power is defined as the power required to drive the rotor at a constant angular velocity $\Omega$ averaged over one revolution,

$$
P_{R}=\frac{\Omega}{2 \pi} \int_{0}^{2 \pi}-M_{H z 1}(\psi) d \psi,
$$

where $M_{H z 1}$ is the total yawing moment about the hub and includes the effect of unsteadiness, compressibility, dynamic stall, and the additional drag due to flap deflection.

The control input $\mathbf{u}$ is related to the output $\mathbf{z}$ through a transfer matrix $\mathbf{T}$ given by

$$
\mathbf{T}=\frac{\partial \mathbf{z}}{\partial \mathbf{u}}
$$

The control strategy is based on the minimization of a performance index that is a quadratic function of the vibration or noise levels $\mathbf{z}$ and the control amplitudes $\mathbf{u}$ :

$$
J\left(\mathbf{z}_{i}, \mathbf{u}_{i}\right)=\mathbf{z}_{i}^{T} \mathbf{W}_{z} \mathbf{z}_{i}+\mathbf{u}_{i}^{T} \mathbf{W}_{u} \mathbf{u}_{i},
$$

where the $\mathbf{W}_{z}$ and $\mathbf{W}_{u}$ are the weighted matrices on the vibration or noise magnitudes and control input, respectively. The subscript $i$ refers to the $i^{\text {th }}$ control step, reflecting the discrete-time nature of the controller. The optimal control is determined by solving the condition for minimization of the cost function $J$ :

$$
\frac{\partial J\left(\mathbf{z}_{i}, \mathbf{u}_{i}\right)}{\partial \mathbf{u}_{i}}=0
$$

which yields the optimal control

$$
\mathbf{u}_{i}=-\mathbf{D}^{-1} \mathbf{T}^{T} \mathbf{W}_{z}\left\{\mathbf{z}_{i-1}-\mathbf{T} \mathbf{u}_{i-1}\right\},
$$

where

$$
\mathbf{D}=\mathbf{T}^{T} \mathbf{W}_{z} \mathbf{T}+\mathbf{W}_{u}
$$

For a perfectly linear system, the algorithm converges to the optimal value in a single step. However, if the helicopter response cannot be represented by a linear system, the algorithm might take multiple steps to converge to the optimal value. Several variants of the HHC algorithm, including a relaxed and an adaptive version, have been shown to improve the robustness of the algorithm to model uncertainties. ${ }^{52}$ In the present study, the relaxed HHC algorithm is used for examining vibration reduction and the relaxed adaptive version of the HHC algorithm is used for noise reduction with the microflap and the conventional flap. To impose saturation limits on the flap deflection, an algorithm developed in Ref. 53 is used. In this approach, the control weighting matrix is adjusted iteratively until the flap deflection is properly constrained. 


\section{Validation Studies}

In this section, the combined aeroelastic-aeroacoustic simulation code using the CFD based ROM is validated against the experimental data obtained in the Higher-harmonic-control Aeroacoustic Rotor Tests (HART) program conducted in the German-Dutch wind tunnel. ${ }^{54}$ The HART rotor is a $40 \%$ dynamically and Mach-scaled model of a 4-bladed hingeless MBB BO-105 main rotor, with $-8^{\circ}$ linear twist and standard rectangular planform. The test setup is depicted in Fig. 5. One of the blades was equipped with pressure transducers so that the blade airloads could be measured at various radial locations. Microphone arrays were placed on a traverse stand at a distance of 1.15 rotor radius underneath the rotor hub, and moved across the horizontal plane to measure the rotor noise at various locations. The rotor was trimmed for a given advance ratio $\mu$, thrust coefficient $C_{T}$, and rotor shaft angle $\alpha_{R}$, using collective and $1 /$ rev cyclic pitch inputs. The baseline condition in HART corresponds to a typical BVI flight condition, with $\mu=0.15, C_{T}=0.044$ and $\alpha_{R}=5.3^{\circ}$.

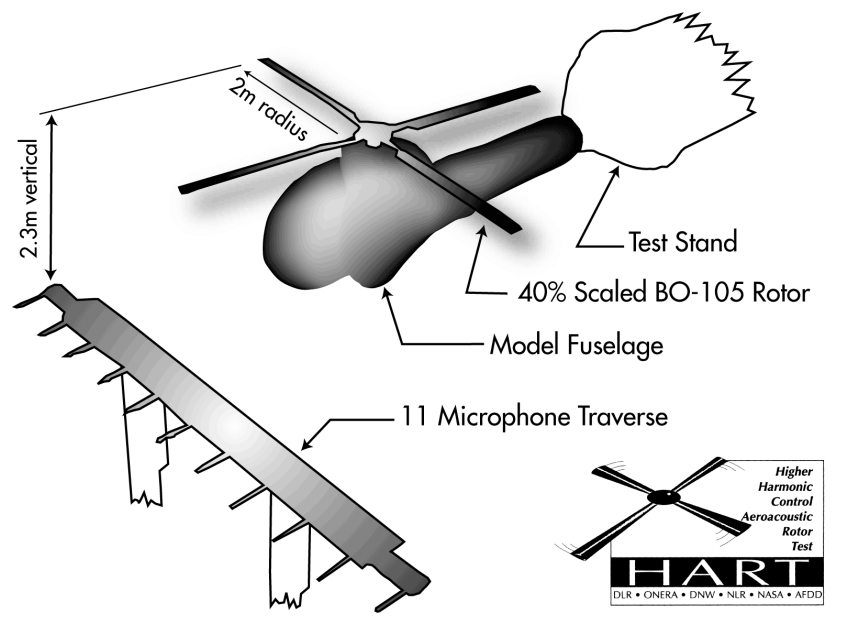

Figure 5. HART test setup.

The aerodynamic loads measured at a location $r / R=0.87$ along the span of the blade obtained from the simulation and those measured in the HART study are compared in Fig. 6. Aerodynamic loads obtained using the original Doublet-Lattice based and the new CFD based aerodynamic models are shown in Fig. 6. The vertical axis in Fig. 6 represents a non-dimensional quantity equal to the product of the normal force coefficient and the square of the local Mach number. Both simulations capture the BVI events represented by the high frequency fluctuations in the aerodynamic loads, also found in the experimental data. Note that the prediction from the CFD+RFA model captures the overall shape of the aerodynamic load time histories better than the DL based aerodynamic model.

As indicated earlier, the acoustic environment was measured by traversing a microphone array positioned 1.15 R below the rotor, as shown in Fig. 5. From these data, time-averaged noise levels in decibel (dB) could be computed on a "carpet plane" parallel to and below the rotor. Comparison of the noise levels obtained from the simulations and the HART experiments is shown in Fig. 7, where the noise predicted by the DL+RFA model is shown from Ref. 50. The magnitudes of the BVI noise levels are predicted reasonably well by both the DL+RFA and CFD+RFA aerodynamic models. However, the DL+RFA model produced better agreement with the experimental data than the CFD+RFA model in the location of the high BVI noise region on the advancing side. Note that the unsteady chordwise pressure distribution is calculated differently for the two models, as noted in Section II.D. The discrepancies observed in Fig. 7 can be attributed to the different pressure calculations.

\section{Results and Discussions}

The results presented in this section are obtained for a helicopter configuration resembling a full-scale four-bladed MBB BO-105 hingeless rotor. The rotor parameters are listed in Table 1. The rotor is trimmed using a propulsive trim procedure. The acoustic environment in the vicinity of the helicopter is obtained by measuring the noise decibel levels on a carpet plane 1.15R beneath the rotor, as depicted in Fig. 8. Noise 


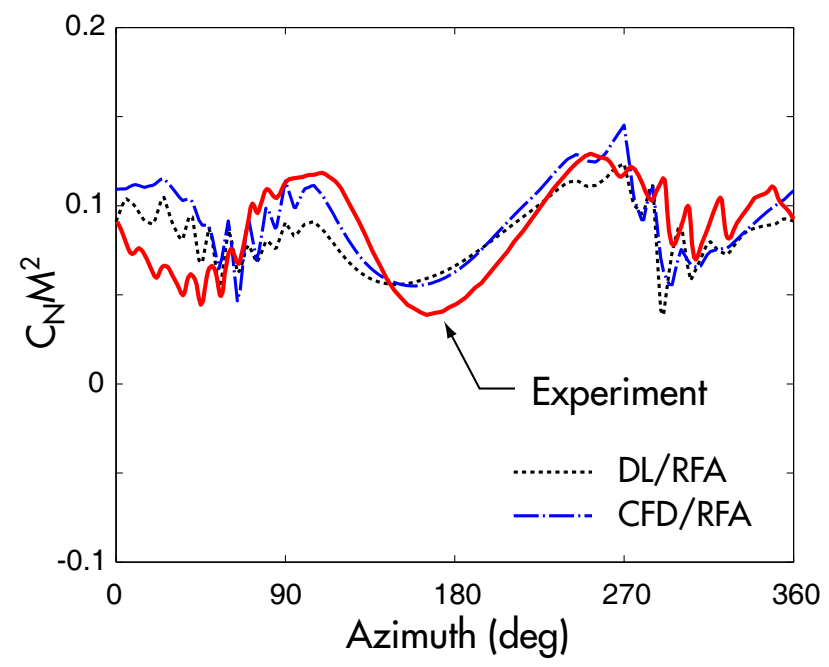

Figure 6. Validation of the aerodynamic load computations with the HART experimental data at $r / R=0.87$.
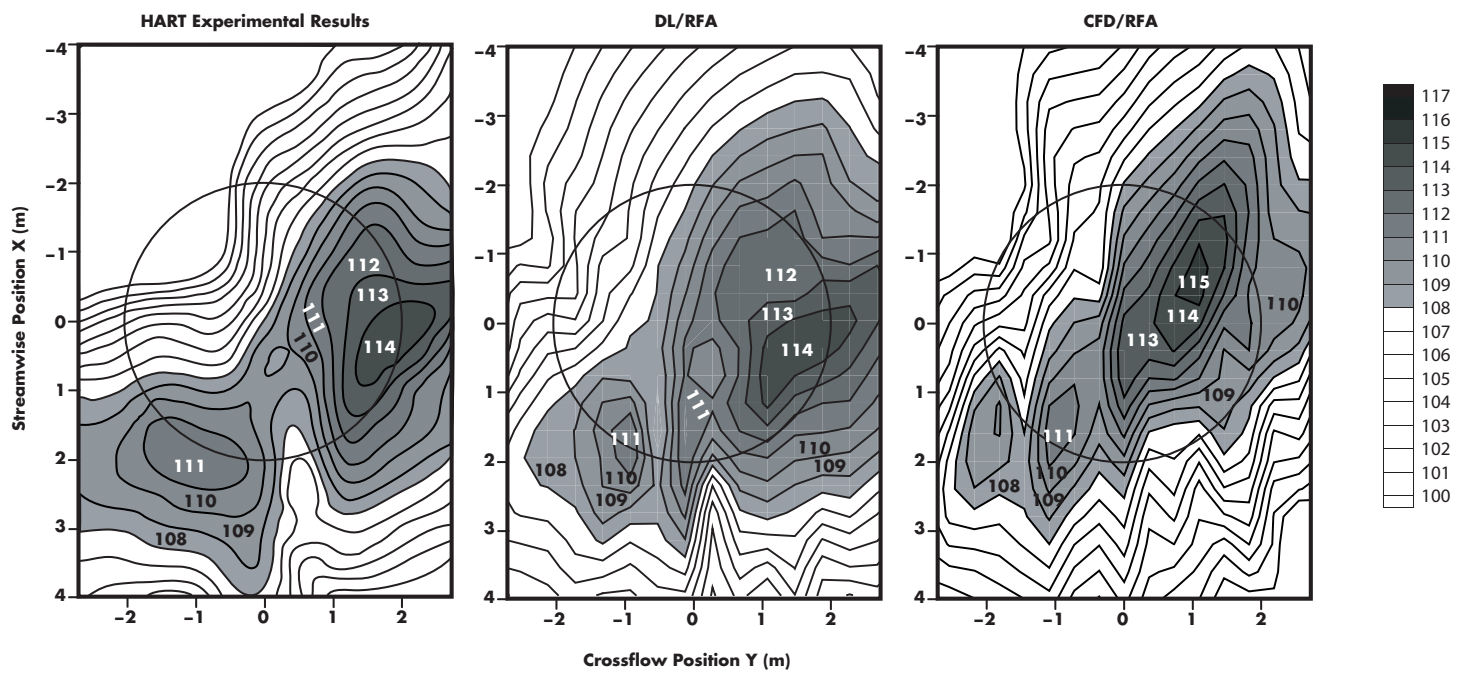

Figure 7. Validation of the acoustic computations with the HART experimental data. 
measured by a microphone placed on the right landing skid at the rear is used as the feedback signal to the controller. The sharp trailing edge configuration, shown in Fig. 9, was chosen as the microflap configuration. The microflap, $1.5 \% \mathrm{c}$ in height, slides in and out of a cavity, located at $6 \% \mathrm{c}$ from the sharp trailing edge of the airfoil.

Table 1. Rotor parameters used for noise and vibration reduction studies.

\begin{tabular}{|c|c|}
\hline Dimensional Rotor Data & \\
\hline$R=4.91 \mathrm{~m}$ & \\
\hline$M_{b}=27.35 \mathrm{~kg}$ & \\
\hline$\Omega=425 \mathrm{RPM}$ & \\
\hline Nondimensional Rotor Data & \\
\hline$N_{b}=4$ & $L_{b}=1.0$ \\
\hline$c / R=0.05498$ & $\theta_{\mathrm{tw}}=-8^{\circ}$ \\
\hline$e=0$ & \\
\hline$X_{A}=0$ & $X_{I b}=0$ \\
\hline$\omega_{F}=1.124,3.40,7.60$ & $\omega_{L}=0.732,4.458$ \\
\hline$\omega_{T}=3.17,9.08$ & \\
\hline$\gamma=5.5$ & $\sigma=0.07$ \\
\hline$\beta_{p}=2.5^{\circ}$ & \\
\hline Helicopter Data & \\
\hline$\overline{C_{W}=0.005}$ & $f C_{d f}=0.031$ \\
\hline$X_{F A}=0.0$ & $Z_{F A}=0.3$ \\
\hline$X_{F C}=0.0$ & $Z_{F C}=0.3$ \\
\hline
\end{tabular}

Three different spanwise configurations of microflaps on the rotor blade are considered in this study. The first configuration, shown in Figure 10(a), has a single microflap with 0.12R spanwise length centered at 0.75R. The second configuration, shown in Figure 10(b), has two microflaps each with 0.06R spanwise length centered at $0.72 \mathrm{R}$ and $0.92 \mathrm{R}$, respectively. The third configuration shown in Figure 10(c), has five microflaps each $0.05 \mathrm{R}$ in spanwise length placed adjacently.

\section{V.A. Noise reduction using microflaps}

Noise reduction studies are conducted using the three microflap configurations described earlier for a heavy BVI descending flight condition with advance ratio $\mu=0.15$ and descent angle $\alpha_{D}=6.5^{\circ}$. The weight coefficient $C_{\mathrm{W}}=0.005$. The adaptive $\mathrm{HHC}$ control algorithm is used to reduce noise levels at the feedback microphone located on the right rear skid. The control input is a combination of the $2 / \mathrm{rev}, 3 / \mathrm{rev}, 4 / \mathrm{rev}$, and $5 /$ rev harmonic components of the microflap deflection. The BVI noise contours on the carpet plane are shown in Fig. 11(a) for the baseline case. The noise levels during active noise control using the single, dual, and the five-microflaps configurations are shown in Figs. 11(b), 11(c), and 11(d), respectively. The single microflap configuration yields up to $3 \mathrm{~dB}$ noise reduction on the advancing side and $2 \mathrm{~dB}$ reduction on the retreating side of the rotor disk. The dual microflap configuration yields up to $5 \mathrm{~dB}$ noise reduction on the advancing side and close to $3 \mathrm{~dB}$ reduction on the retreating side. Clearly, it is beneficial for noise reduction to have a control device placed closer to the blade tip as in the case of the dual microflap configuration. The five-microflaps configuration reduces the advancing side noise by almost $6 \mathrm{~dB}$ and the retreating side noise by $3 \mathrm{~dB}$. It is interesting to note that the BVI noise is reduced by the microflap configurations for the whole carpet plane; this is in contrast to the earlier active control studies performed using the single and dual conventional ACFs, where a noise increase of $1-2 \mathrm{~dB}$ on the retreating side was observed. ${ }^{18}$ Overall, significant control authority is demonstrated by the microflaps for rotorcraft noise reduction.

The vibration levels were also monitored during the active noise reduction process. The vibration levels obtained after active noise reduction using the single, dual, and five-microflaps configurations are compared to the baseline vibration levels in Fig. 12. The vertical hub shear is increased by $45 \%$ in the case of the single and dual microflap configurations and by $100 \%$ in the case of the five-microflaps configuration. An increase 

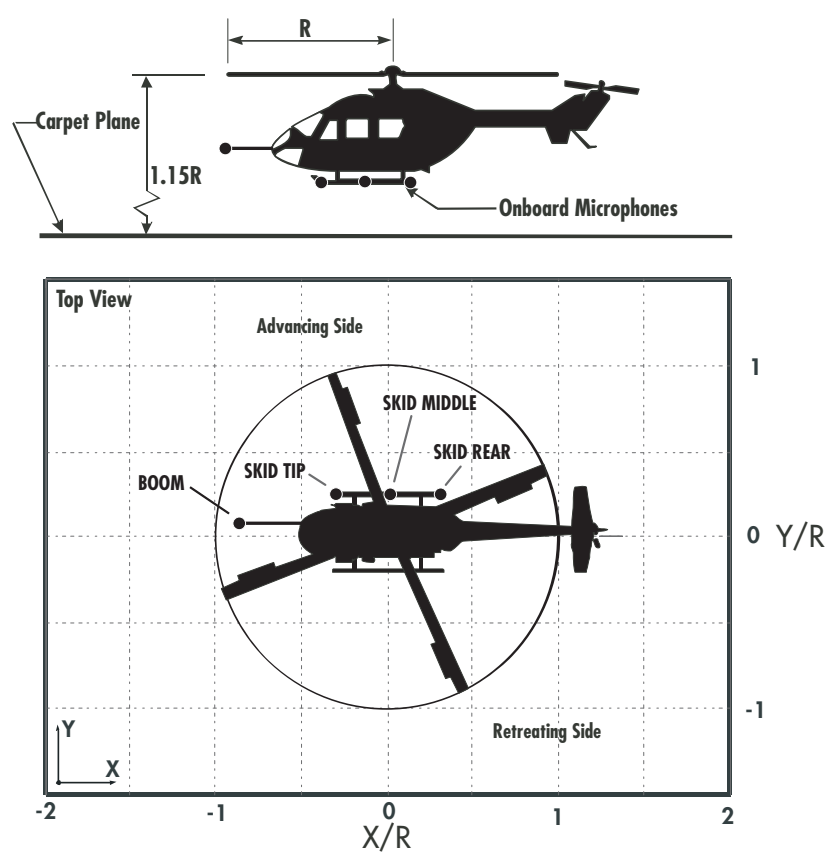

Figure 8. Microphone locations on and around the helicopter for noise measurements.

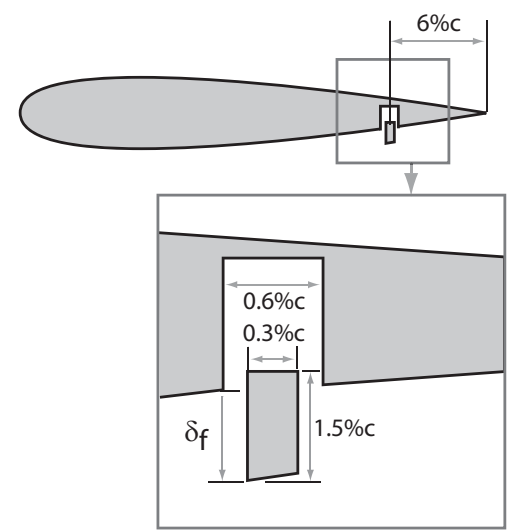

Figure 9. Oscillating microflap in a cavity depicting the sharp trailing-edge configuration. 


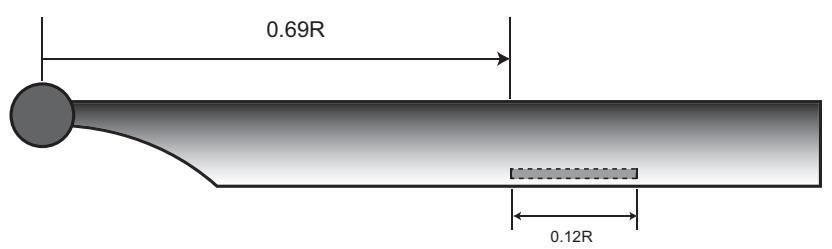

(a) Single Microflap

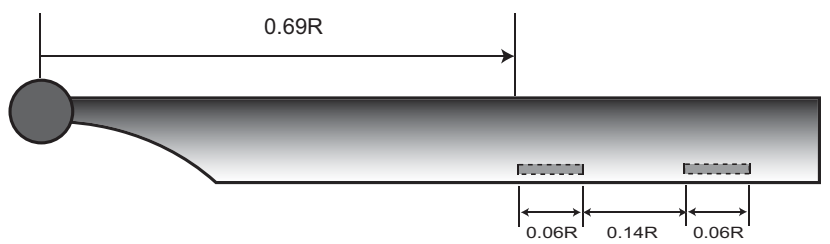

(b) Dual Microflap

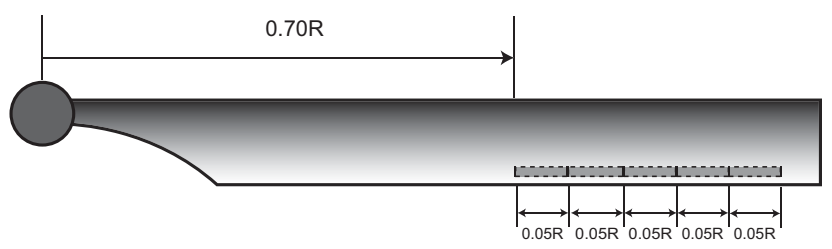

(c) Five Microflaps

Figure 10. Various spanwise configurations of the microflap on the rotor blade

in vibration levels during active noise reduction was also observed in the earlier active control studies using conventional plain flaps, ${ }^{18,20}$ as well as in noise control studies using other active control approaches. ${ }^{54}$

The microflap deflection histories for the single and dual microflap configurations over one complete revolution are shown in Figures 13(a) and 13(b). The saturation algorithm described earlier is used to restrain the microflap deflection between $0 \% \mathrm{c}$ and $1.5 \% \mathrm{c}$ which correspond to the retracted and fully deployed positions of the microflap.

Next, the noise reduction capabilities of the microflap are compared to those of a $20 \%$ c trailing-edge plain flap. The plain flap deflections are constrained between $\pm 4^{\circ}$. The noise levels measured on the carpet plane during active noise control using the single microflap and the single plain flap configurations are shown in Figs. 14(b), 14(c). It is interesting to note that although the plain flap and the microflap configurations seem to yield similar overall reductions on the advancing side, the single plain flap yields $1 \mathrm{~dB}$ less reduction on the retreating side when compared to the single microflap configuration. The vibration levels measured during active noise control using the single plain flap and the single microflap configurations are compared to the baseline levels in Fig. 15. The vertical hub shear is increased by $23 \%$ in the case of the plain flap and by $45 \%$ in the case of the microflap.

The flap deflection histories for the single microflap and the single plain flap configurations over one complete revolution are shown in Figures 16(a) and 16(b), respectively. It is evident that the flap deflection histories are fairly similar in overall shape, which is not surprising since the control devices are located at the same spanwise location on the blades.

\section{V.B. Vibration reduction using microflaps}

In this section, vibration reduction with various microflap configurations is examined for the same flight condition as in the previous section, with advance ratio $\mu=0.15$ and descent angle $\alpha_{D}=6.5^{\circ}$. The relaxed HHC control algorithm is used to reduce the $4 /$ rev vibratory hub loads. The control input is a combination of the $2 / \mathrm{rev}, 3 / \mathrm{rev}, 4 / \mathrm{rev}$, and $5 / \mathrm{rev}$ harmonic components of the microflap deflection. The baseline vibratory hub shears and moments as well as the reduced vibrations obtained using the three microflap configurations are shown in Fig. 17. All three configurations yield a significant reduction in the vibration levels demonstrating excellent control authority. The single microflap yields a $70 \%$ reduction in the vibration objective, while the dual microflap and the five-microflaps configurations produce $84 \%$ and 

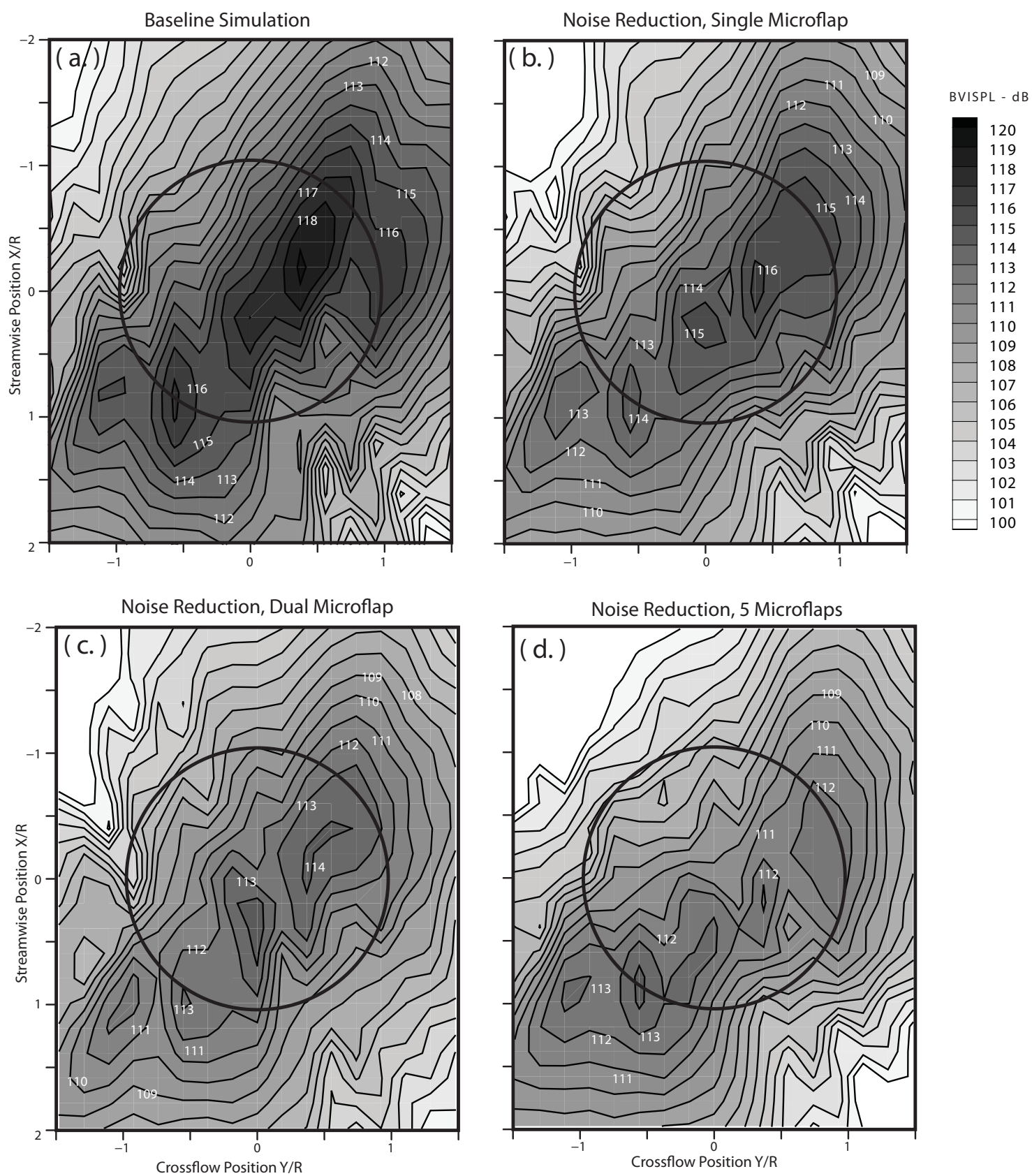

Figure 11. Noise levels measured on the carpet plane during active noise reduction using microflaps. 


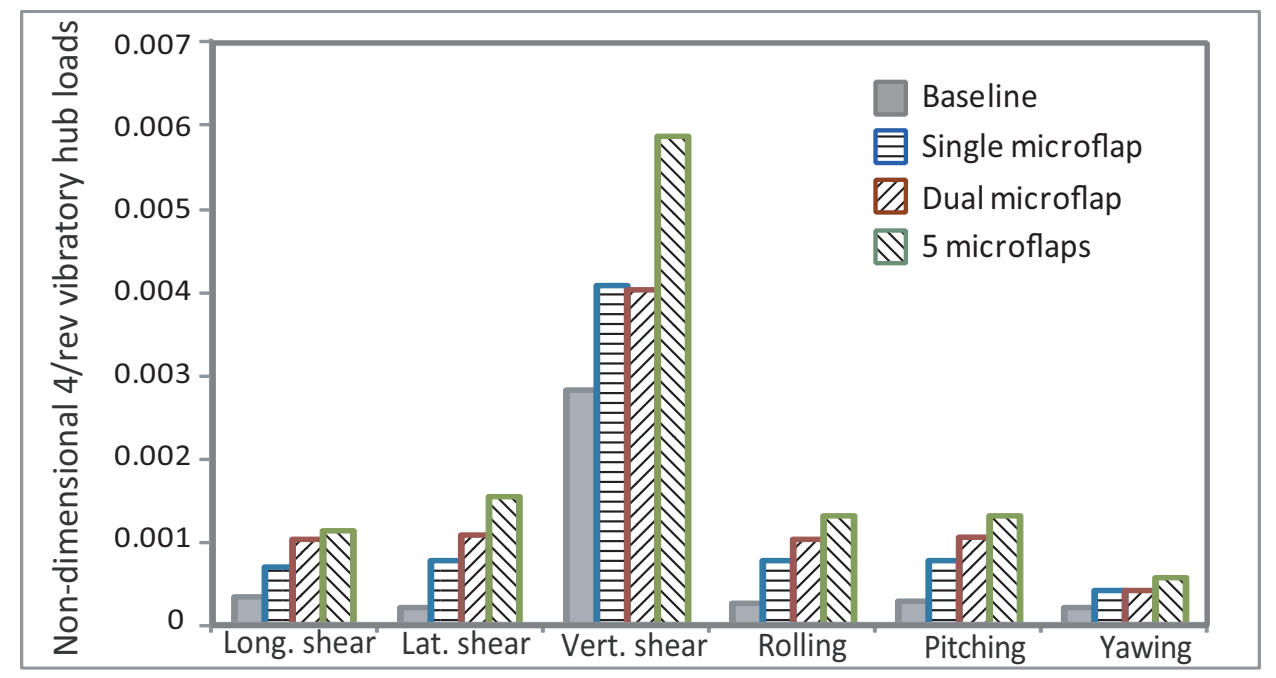

Figure 12. Vibration levels during active noise reduction using microflaps.

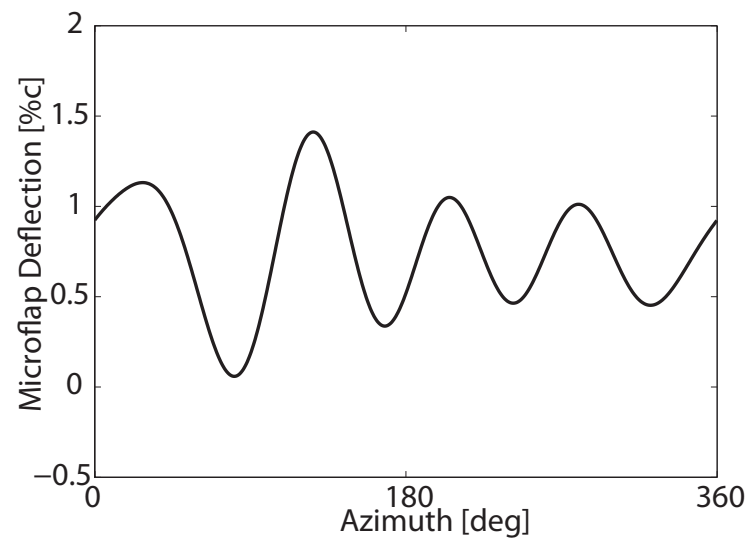

(a) Single microflap

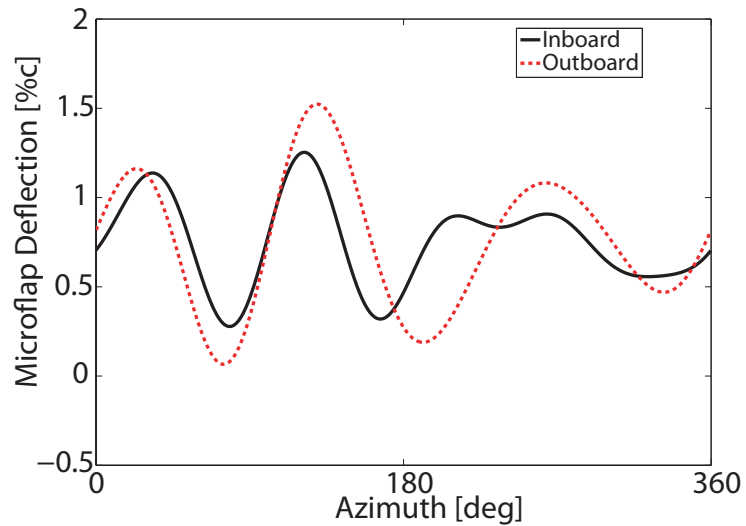

(b) Dual microflap

Figure 13. Microflap deflection histories over one complete revolution for the single and dual microflap configurations during active noise reduction.
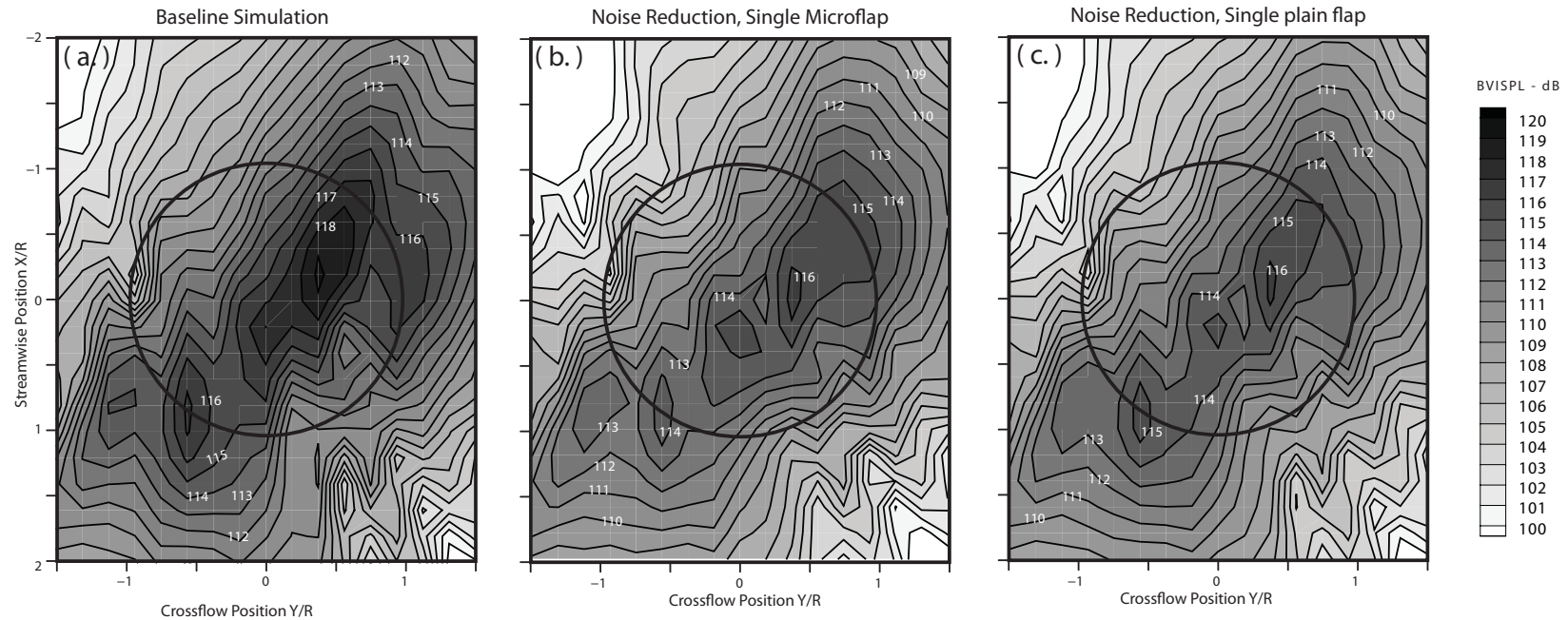

Figure 14. Comparison of the noise levels measured on the carpet plane during active noise control using a single microflap and a single plain flap. 


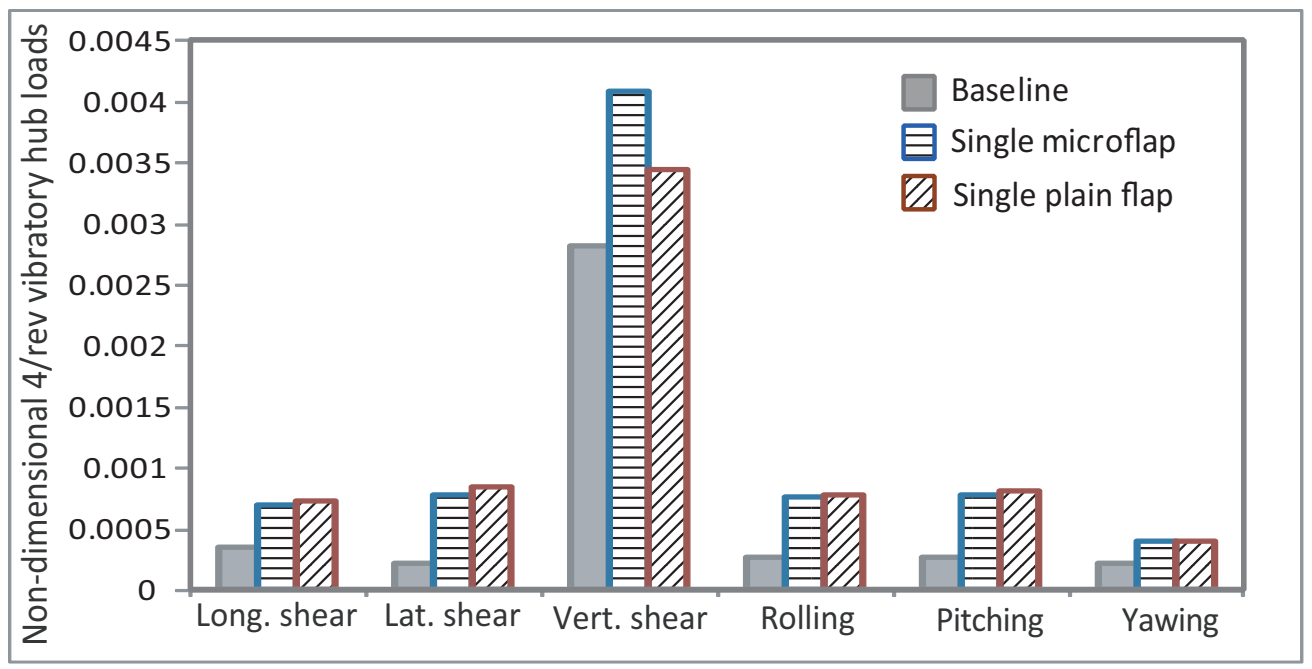

Figure 15. Comparison of the vibration levels measured during active noise control using a single microflap and a single plain flap.

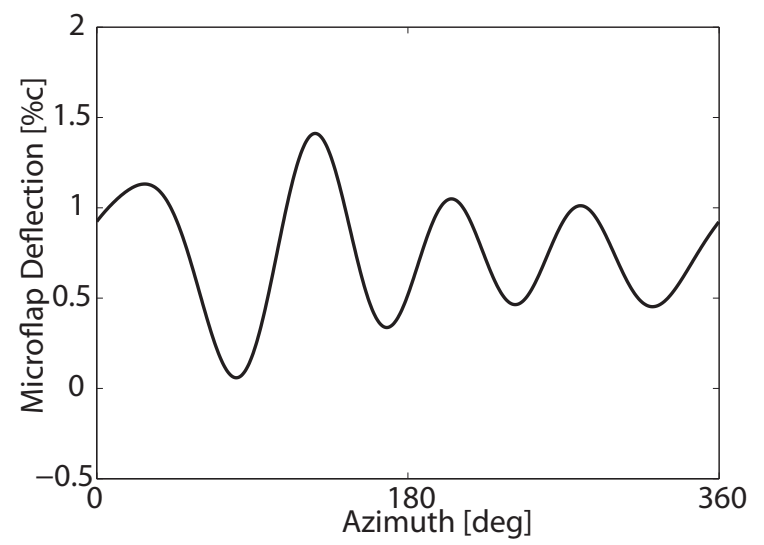

(a) Single microflap

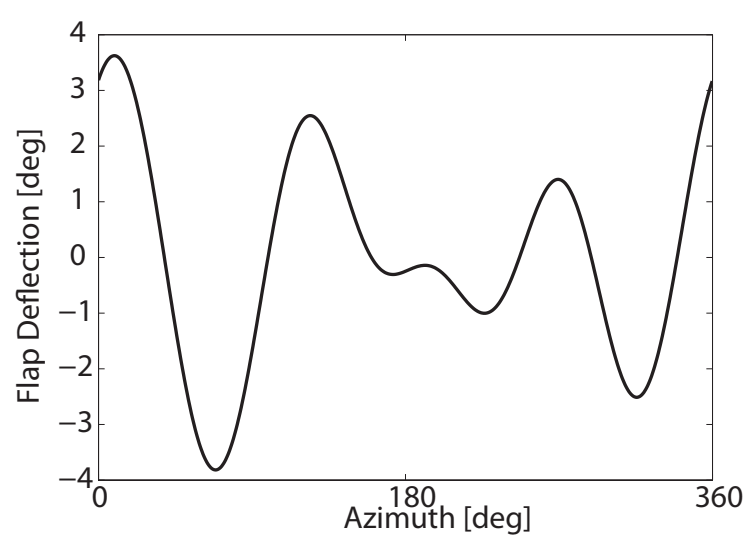

(b) Single plain flap

Figure 16. Microflap deflection histories over one complete revolution for the single microflap and the single plain flap configurations during active noise reduction. 
$92 \%$ reduction, respectively. Note that the vibration objective is a weighted sum of the squares of the $4 / \mathrm{rev}$ vibratory hub shears and moments.

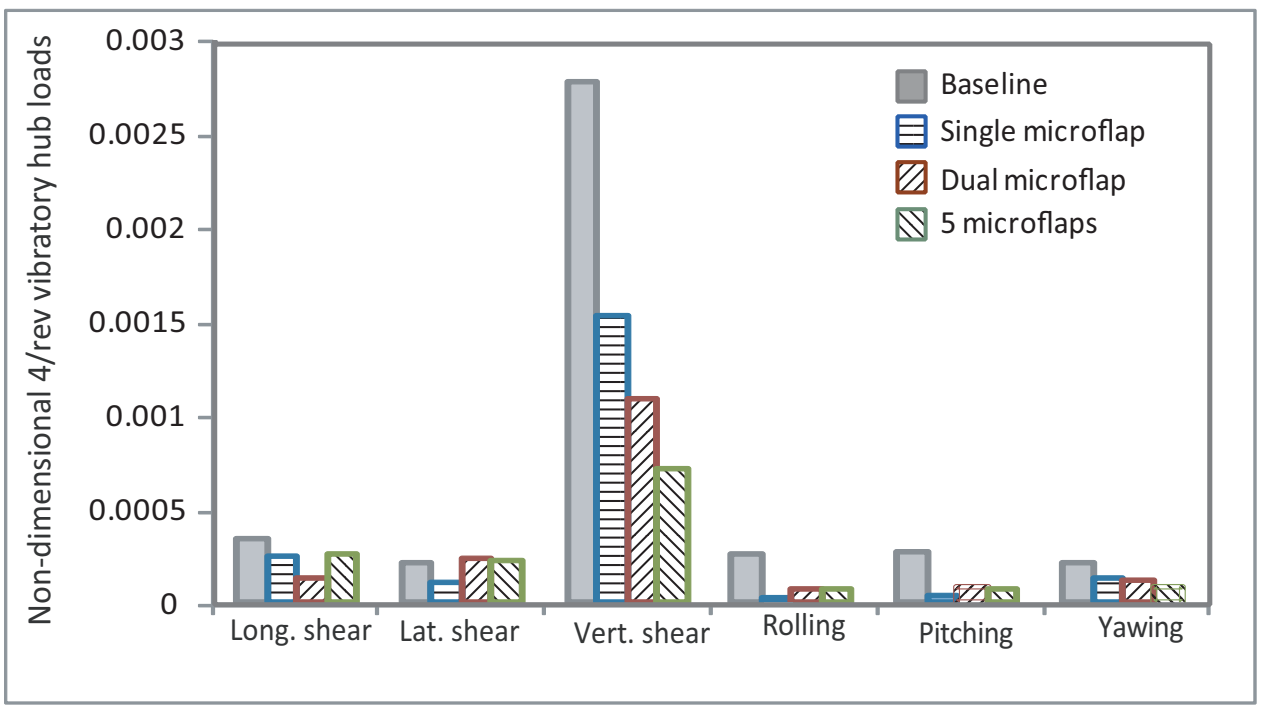

Figure 17. Reduction in $4 /$ rev vibratory hub shears and moments obtained using the single, dual, and 5 microflap configurations for a heavy BVI descending flight condition.

The microflap deflection histories for the single and dual microflap configurations over one complete revolution are shown in Figs. 18(a) and 18(b). Compared to the optimal inputs for noise reduction shown earlier in Fig. 13, the control inputs for best vibration reduction evidently contain more higher harmonic components $(4 /$ rev and $5 /$ rev $)$.

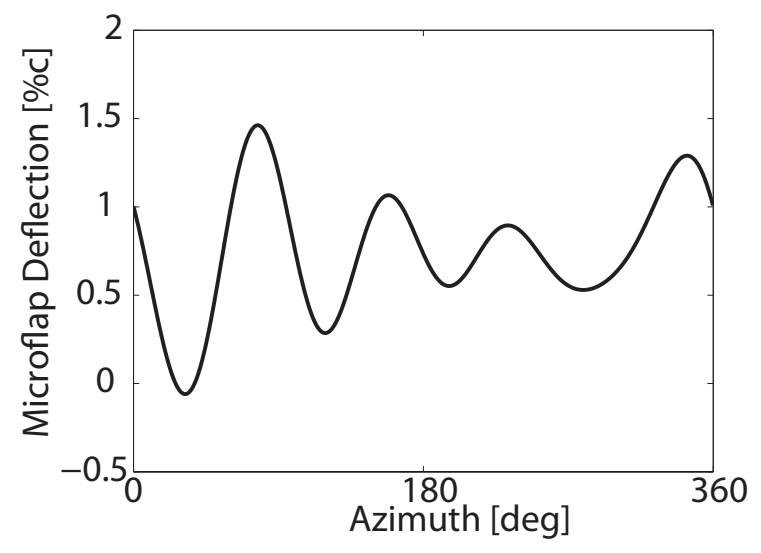

(a) Single microflap

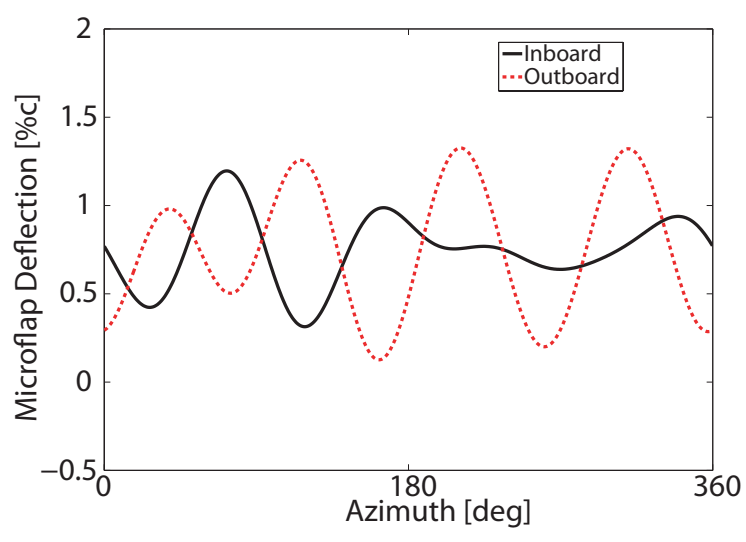

(b) Dual microflap

Figure 18. Microflap deflection histories over one complete revolution for the single and dual microflap configurations during active vibration reduction at BVI flight conditions.

The noise levels on the carpet plane were also measured during active vibration reduction using microflaps. The noise generated during active vibration reduction using the single, dual, and five-microflaps configurations are shown in Figs. 19 (b), 19 (c), and 19 (d), respectively. During vibration reduction, the single microflap generated a significant increase of about 2-3 dB in the noise levels on the advancing side. By comparison, the dual microflap configuration produced a smaller noise penalty on the advancing side noise of about $1 \mathrm{~dB}$. It is very interesting to note that the five-microflaps configuration does not produce a noise penalty. The noise levels on the retreating side are not affected significantly by any of the three configurations. 

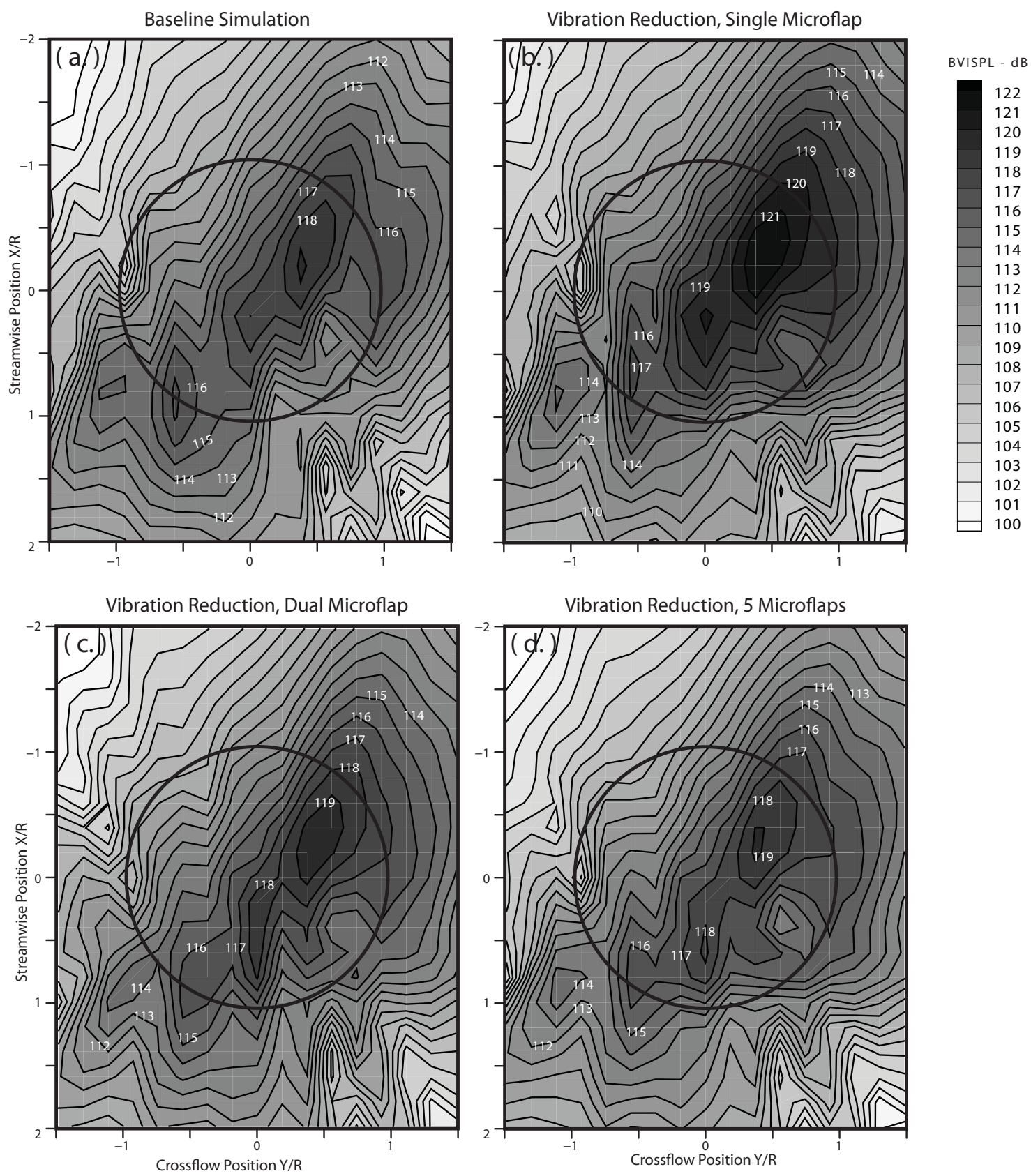

Figure 19. Noise levels measured on the carpet plane during active vibration reduction using microflaps at BVI flight conditions. 


\section{V.C. Vibration reduction at a high advance ratio}

In this section, results for vibration reduction with various microflap configurations are presented for a high speed cruise flight with $\mu=0.3$ and weight coefficient $C_{\mathrm{W}}=0.005$. These results are obtained for the same rotor configuration used earlier with parameters listed in Table 1.

Vibratory hub loads obtained using the single, dual, and five-microflaps configurations, illustrated in Figs. 10(a)-10(c), are shown in Fig. 20. All three configurations considered here produce a substantial amount of vibration reduction, again demonstrating the control authority of the microflap at the cruise flight condition. The single and dual microflap configurations yield similar reduction levels of $92 \%$ in the vibration objective. The five-microflaps configuration also provides a very similar $93 \%$ reduction in the overall vibration levels, as can be seen from Fig. 20.

The microflap deflection histories for the single and dual microflap configurations over one complete revolution are shown in Figs. 21(a) and 21(b), respectively. The microflap deflection is restricted between $0 \% \mathrm{c}$ and $1.5 \% \mathrm{c}$. The maximum deflection of the outboard flap in the dual flap configuration is significantly less than $1.5 \% \mathrm{c}$, suggesting that the control weighting may be adjusted to produce more vibration reduction for the dual flap configuration.

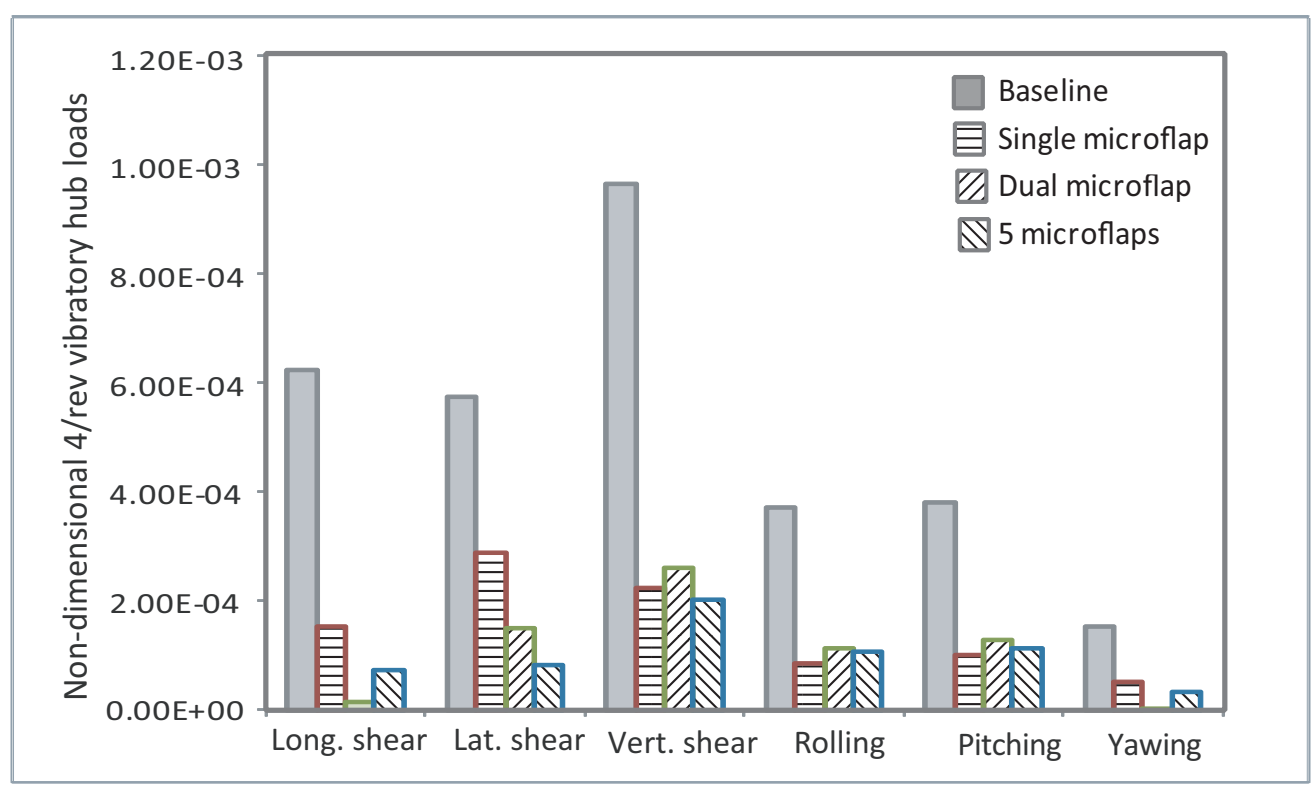

Figure 20. Reduction in $4 / \mathrm{rev}$ vibratory hub shears and moments obtained using the single, dual, and 5 microflap configurations at a high speed forward flight condition.

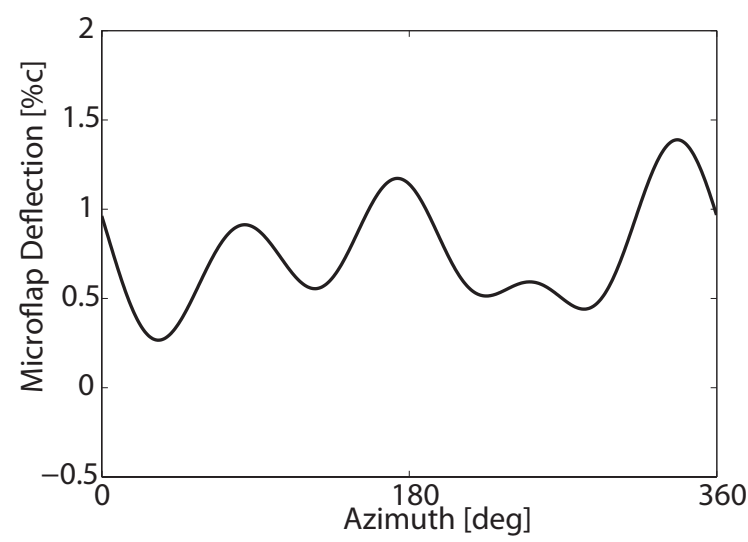

(a) Single microflap

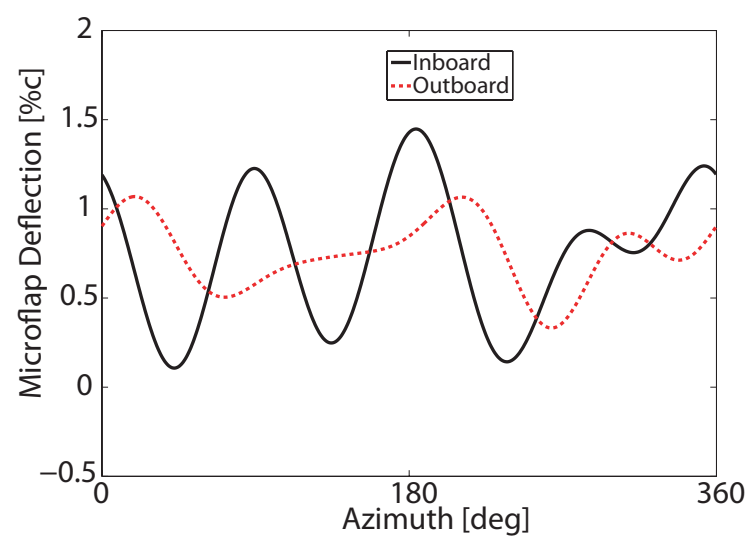

(b) Dual microflap

Figure 21. Microflap deflection histories over one complete revolution for the single and dual microflap configurations during active vibration reduction at a high speed forward flight condition. 
Next, the vibration reduction capabilities of the microflap are compared to those of a 20\%c trailing-edge plain flap for this flight condition. Vibration levels obtained using the single and dual flap configurations of the conventional plain flap and the microflap are shown in Figure 22. The single plain flap and the single microflap configurations yield $94 \%$ and $92 \%$ reduction in the vibration objective, respectively. The dual plain flap and the dual microflap configurations yield $96 \%$ and $92 \%$ reduction in the vibration objective, respectively. Therefore, the overall vibration reduction levels using the microflaps and conventional ACFs are similar. It is also important to note that the single and dual microflap configurations incur $3.4 \%$ and $5.3 \%$ performance penalties as evidenced by the increased rotor power requirement, during active vibration reduction at the cruise condition. By comparison, the corresponding plain flap configurations incur less than $1 \%$ performance penalty during vibration reduction. This significant penalty in rotor performance during vibration reduction has been identified in our previous studies to be a result of higher sectional drag incurred by the microflaps during its deployment, and may be reduced using a smaller microflap deflection (less than $1 \% \mathrm{c}) .{ }^{32}$

The plain flap deflection histories for the single and dual flap configurations over one complete revolution are shown in Figures 23(a) and 23(b), respectively. The angular deflection of the plain flap is restricted to $\pm 4^{\circ}$ as practical saturation limits. The plain flap deflection histories display a notable resemblance to the microflap deflection histories (see Fig. 21), where the peaks and troughs of the deflections occur at approximately same azimuthal locations.

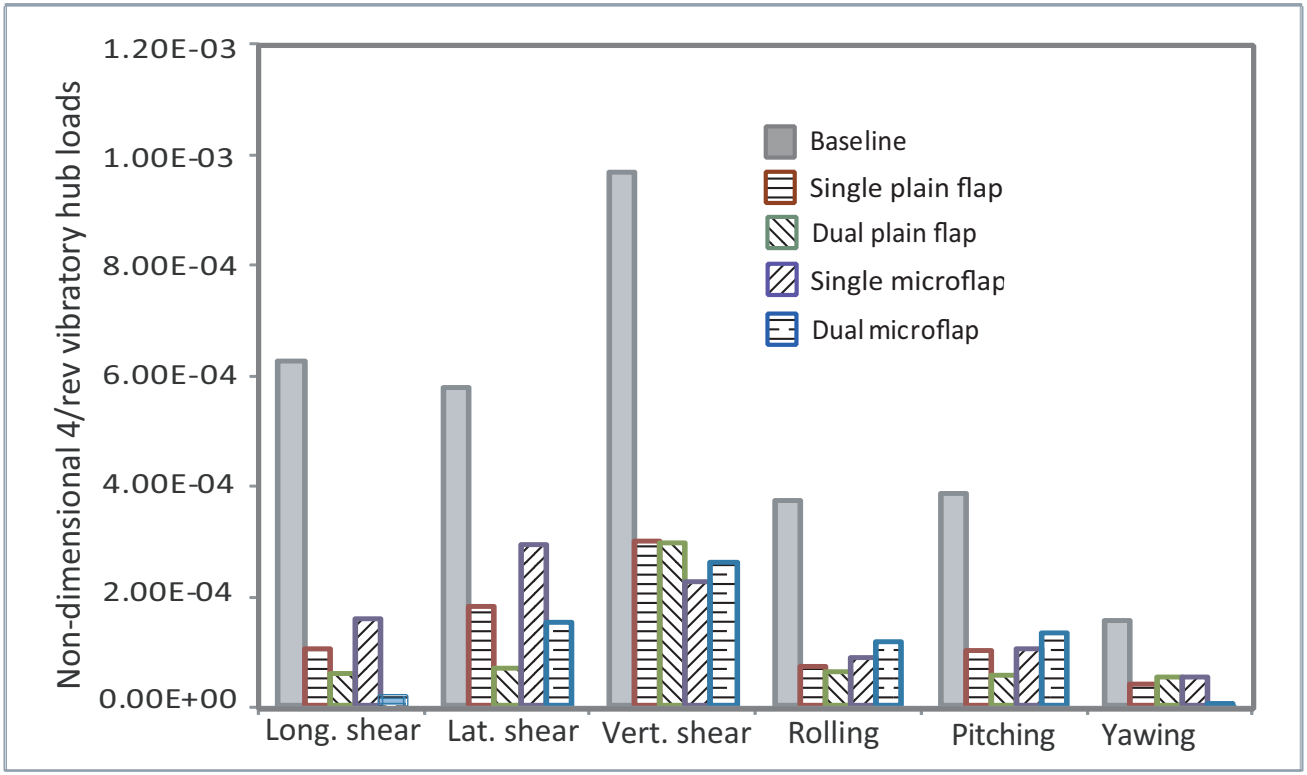

Figure 22. Reduction in $4 / \mathrm{rev}$ vibratory hub shears and moments obtained using the single and dual flap configurations of the $20 \%$ c trailing-edge plain flap and the $1.5 \%$ c microflap at a high speed forward flight condition.

\section{V.D. Performance enhancement using microflaps}

In this section, the effect of microflaps on rotorcraft performance at a high speed flight condition with $\mu=0.30$ is examined. As was mentioned earlier, vibration reduction using microflaps at a high speed forward flight condition results in a significant performance penalty. To further examine the effect of microflaps on rotor performance, closed loop control studies were conducted with a combined objective function consisting of both vibratory loads and rotor power. The combined output vector in the controller is now defined as

$$
\mathbf{z}=\left[\begin{array}{lllllll}
F_{H X 4} & F_{H Y 4} & F_{H Z 4} & M_{H X 4} & M_{H Y 4} & M_{H Z 4} & P_{R}
\end{array}\right]^{T},
$$




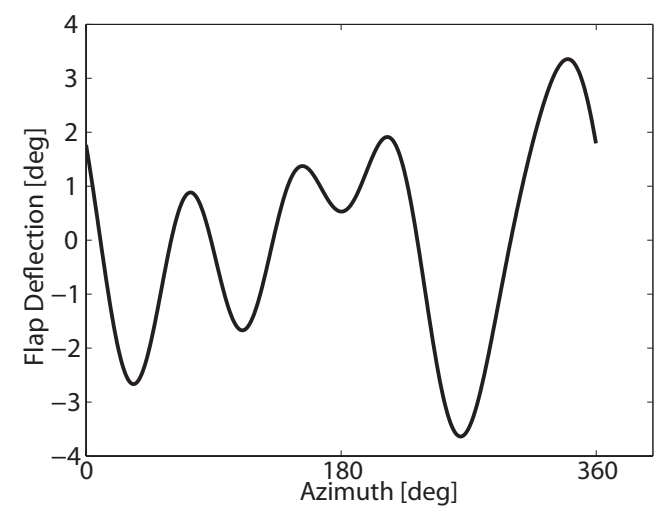

(a) Single plain flap

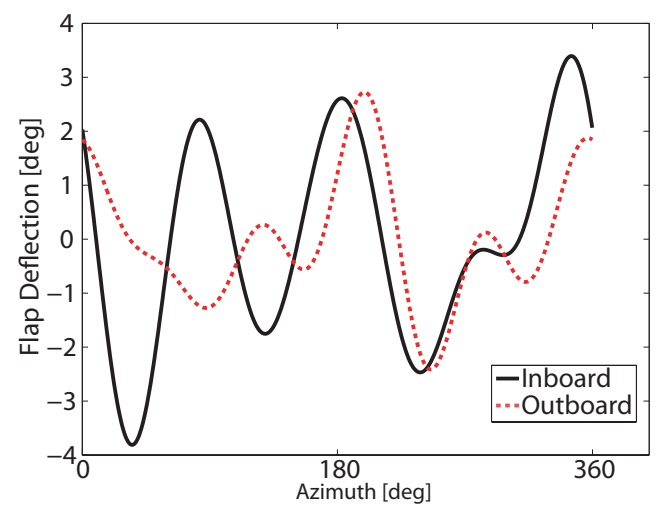

(b) Dual plain flap

Figure 23. Flap deflection histories over one complete revolution for the single and dual plain flap configurations during active vibration reduction at a high speed forward flight condition..

The weighting $\mathbf{W}_{z}$ (see Eqn. 18) on the output vector is given by

$$
\mathbf{W}_{z}=\left[\begin{array}{ccccccc}
W_{\alpha} & 0 & 0 & 0 & 0 & 0 & 0 \\
0 & W_{\alpha} & 0 & 0 & 0 & 0 & 0 \\
0 & 0 & W_{\alpha} & 0 & 0 & 0 & 0 \\
0 & 0 & 0 & W_{\alpha} & 0 & 0 & 0 \\
0 & 0 & 0 & 0 & W_{\alpha} & 0 & 0 \\
0 & 0 & 0 & 0 & 0 & W_{\alpha} & 0 \\
0 & 0 & 0 & 0 & 0 & 0 & 1-W_{\alpha}
\end{array}\right]
$$

where the parameter $W_{\alpha}$ is used to vary the relative weighting between the vibratory loads and the rotor power. Note that all the vibratory hub shears and moments are penalized equally. For a preliminary study, the single microflap configuration is used and it is employed for control of the combined vibration and power objective. Changes in vibration levels and the corresponding changes in the rotor power obtained for various values of $W_{\alpha}$ are listed in Table 2. The rotor power consumption may be reduced by $0.57 \%$ and $1.2 \%$ for $W_{\alpha}$ values of 0.3 and 0.25 , respectively. The reduced power requirement indicates that the microflaps has potential for performance enhancement. However, the reductions in rotor power consumption are also accompanied by increases in the $4 / \mathrm{rev}$ vibratory hub loads by $78 \%$ and $171 \%$, respectively, as shown in the table. The vibratory hub loads corresponding to several values of $W_{\alpha}$ are shown in Fig. 24. The longitudinal and lateral shear forces are significantly increased during performance enhancement, particularly for the relative weight $W_{\alpha}=0.25$. Also note that for the single microflap configuration and the relative weighting range considered here, simultaneous vibration reduction and performance enhancement was not found.

Table 2. Effect of a single microflap on the vibratory hub loads and the rotor performance using a combined objective function.

\begin{tabular}{|c|c|c|c|c|c|}
\hline \hline$W_{\alpha}$ & 0.45 & 0.4 & 0.35 & 0.3 & 0.25 \\
\hline Baseline power & 0.00519928 & 0.00519928 & 0.00519928 & 0.00519928 & 0.00519928 \\
\hline $\begin{array}{c}\text { Power after } \\
\text { active control }\end{array}$ & 0.0052977 & 0.00527816 & 0.00521893 & 0.00516958 & 0.00513685 \\
\hline $\begin{array}{c}\% \text { change in } \\
\text { Power }\end{array}$ & 1.89 & 1.51 & 0.37 & -0.57 & -1.2 \\
\hline $\begin{array}{c}\% \text { change in } \\
\text { Vibrations }\end{array}$ & -33 & -8 & 8 & 78 & 171 \\
\hline \hline
\end{tabular}




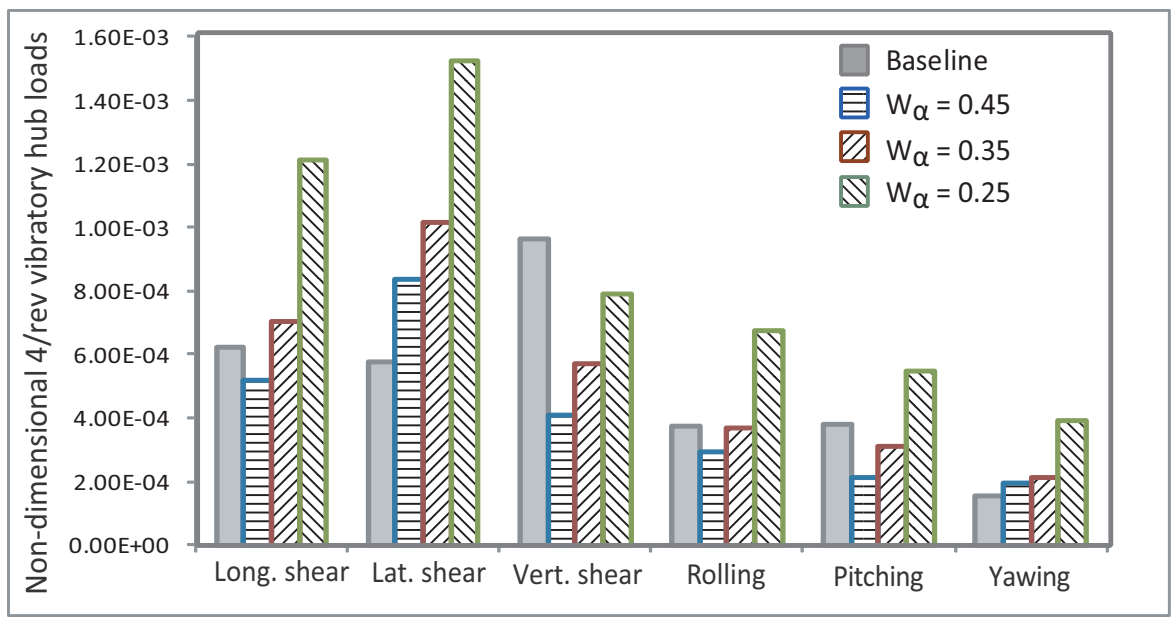

Figure 24. Effect of a single microflap on the vibratory hub loads during active control of vibrations and rotor performance using a combined objective function.

\section{Conclusions}

The control authority of microflaps as on-blade control of noise and vibration in rotorcraft was examined. A comprehensive rotorcraft simulation code AVINOR was employed which uses a CFD based reduced-order aerodynamic model for modeling the microflaps. Based on earlier research, a sliding microflap configuration with a $1.5 \%$ c height was selected for active control studies. Three span-wise microflap configurations are considered: single, dual, and a segmented five-flap configuration. The HHC control algorithm was employed for active noise and vibration reduction studies in closed loop. Active noise reduction using the microflaps was conducted under a heavy BVI descending flight condition with the advance ratio $\mu=0.15$ and descent angle $\alpha_{D}=6.5^{\circ}$. The primary findings of the study are summarized below:

1. The microflap is effective in reducing BVI noise. Depending on the configurations, 3-6 dB noise reduction was achieved on the advancing side and 2-3 dB reduction was shown on the retreating side.

2. It was also found that active noise reduction using microflaps resulted in an increase in the $4 / \mathrm{rev}$ vertical rotor hub shears. The similar trend has been identified computationally and experimentally with other active approaches such as the HHC and the ACF. 18,20,54 The single and dual microflap configurations caused a $45 \%$ increase in the vertical shear whereas the five-microflap configuration resulted in a $100 \%$ increase in the vertical shear.

3. The $1.5 \%$ c microflap demonstrates similar effectiveness when compared to a single $20 \%$ c plain flap configuration for noise reduction capabilities.

4. When used for vibration reduction at the heavy BVI condition, the single microflap configuration produced a 2-3 dB noise penalty on the carpet plane. However, this penalty was reduced for the dual and five-microflaps configurations. The single, dual, and the five-microflaps configurations yield $70 \%, 84 \%$, and $92 \%$ reduction in the vibration objective, respectively, demonstrating very good control authority for rotorcraft vibration reduction.

5. At a high speed cruise condition with $\mu=0.3$, all three spanwise microflap configurations yield over $90 \%$ reduction in the vibration objective.

6. The microflaps were also considered for rotor performance enhancement at the high speed forward flight condition with $\mu=0.3$, using closed loop control with combined vibration and rotor power objectives. A $1.2 \%$ performance enhancement was observed using the single microflap configuration, which was also accompanied by a $170 \%$ increase in the $4 /$ rev vibratory hub loads.

Clearly, these conclusions have demonstrated the effectiveness and control authority of the microflap for multiobjective control in rotorcraft and established the microflap as a viable active device for on-blade rotor control. 


\section{Acknowledgments}

This research was supported by the Vertical Lift Research Center of Excellence (VLRCOE) sponsored by NRTC and U.S. Army with Dr. M. Rutkowski as grant monitor.

\section{References}

${ }^{1}$ Liebeck, R. H., "Design of Subsonic Airfoils for High Lift," Journal of Aircraft, Vol. 15, No. 9, Sept 1978, pp. 547-561.

${ }^{2}$ Storms, B. L. and Jang, C. S., "Lift Enhancement of an Airfoil Using a Gurney Flap and Vortex Generators," Journal of Aircraft, Vol. 31, No. 3, May-June 1994, pp. 542-547.

${ }^{3}$ Baker, J. P., Standish, K. J., and van Dam, C. P., "Two-Dimensional Wind Tunnel and Computational Investigation of a Microtab Modified Airfoil," Journal of Aircraft, Vol. 44, No. 2, March-April 2007, pp. 563-572.

${ }^{4}$ Maughmer, M. D. and Bramesfeld, G., "Experimental Investigation of Gurney Flaps," Journal of Aircraft, Vol. 45, No. 6, November-December 2008, pp. 2062-2067.

${ }^{5}$ Giguere, P., Lemay, J., and Dumas, G., "Gurney Flap Effects and Scaling for Low-speed Airfoils," Proceedings of the AIAA Applied Aerodynamics Conference, San Diego, June 1995.

${ }^{6}$ Jang, C. S., Ross, J. C., and Cummings, R. M., "Numerical Investigation of an Airfoil With a Gurney Flap," Journal of Aircraft Design, Vol. 1, No. 2, June 1998, pp. 75-88.

${ }^{7}$ Chow, R. and van Dam, C. P., "Unsteady Computational Investigations of Deploying Load Control Microtabs," Journal of Aircraft, Vol. 43, No. 5, Sept-Oct 2006, pp. 641-648.

${ }^{8}$ Lee, H.-T., Kroo, I. M., and Bieniawski, S., "Flutter Suppression for High Aspect Ratio Flexible Wings Using Microflaps," Proceedings of the 43rd AIAA/ASME/ASCE/AHS/ACS Structures, Structural Dynamics and Materials Conference, Reno, NV, Apr 2002, AIAA Paper No. 2002-1717.

${ }^{9}$ Kroo, I. M., "Aerodynamic Concepts for Future Aircraft," Proceedings of the 30th AIAA Fluid Dynamics Conference, Norfolk, VA, Jun-July 1999, AIAA Paper No. 99-2003.

${ }^{10}$ Matalanis, C. G. and Eaton, J. K., "Wake Vortex Alleviation Using Rapidly Actuated Segmented Gurney Flaps," AIAA Journal, Vol. 45, No. 8, Aug. 2007, pp. 1874-1884.

${ }^{11}$ Vey, S., Paschereit, O. C., Greenblatt, D., and Meyer, R., "Flap Vortex Management by Active Gurney Flaps," Proceedings of the 46th AIAA Aerospace Sciences Meeting and Exhibit, Reno, NV, Jan 2008, AIAA Paper No. 2008-286.

${ }^{12}$ Nikolic, V. R., "Two Aspects of the Use of Full- and Partial-Span Gurney Flaps," Journal of Aircraft, Vol. 44, No. 5, Sept-Oct 2007, pp. 1745-1748.

${ }^{13}$ Nakafuji, D. T. Y., van Dam, C. P., Smith, R. L., and Collins, S. D., "Active Load Control for Airfoils using Microtabs," Journal of Solar Energy Engineering, Vol. 123, No. 4, November 2001, pp. 282-289.

${ }^{14}$ Wilson, D. G., Berg, D. E., Li, D. W., and Zayas, J. R., "Optimized Active Aerodynamic Blade Control for Load Alleviation on Large Wind Turbines," AWEA WINDPOWER 2008 Conference 8 Exhibition, Houston, TX, June 1-4 2008.

${ }^{15}$ Friedmann, P. P. and Millott, T. A., "Vibration Reduction in Rotorcraft Using Active Control: A Comparison of Various Approaches," Journal of Guidance, Control, and Dynamics, Vol. 18, No. 4, July-August 1995, pp. 664-673.

${ }^{16}$ Friedmann, P. P., de Terlizzi, M., and Myrtle, T. F., "New Developments in Vibration Reduction with Actively Controlled Trailing Edge Flaps," Mathematical and Computer Modelling, Vol. 33, 2001, pp. 1055-1083.

${ }^{17}$ Koratkar, N. A. and Chopra, I., "Wind Tunnel Testing of a Smart Rotor Model with Trailing Edge Flaps," Journal of the American Helicopter Society, Vol. 47, No. 4, Oct. 2002, pp. 263-272.

${ }^{18}$ Patt, D., Liu, L., and Friedmann, P. P., "Simultaneous Vibration and Noise Reduction in Rotorcraft Using Aeroelastic Simulation," Journal of the American Helicopter Society, Vol. 51, No. 2, April 2006, pp. 127-140.

${ }^{19}$ Roth, D., Enenkl, B., and Dieterich, O., "Active Rotor Control by Flaps for Vibration Reduction - Full Scale Demonstrator and First Flight Test Results," Proceedings of the 32nd European Rotorcraft Forum, Maastricht, The Netherlands, September $12-142006$

${ }^{20}$ Straub, F. K., Anand, V. R., Birchette, T. S., and Lau, B. H., "Wind Tunnel Test of the SMART Active Flap Rotor," Proceedings of the 65th Annual AHS Forum, Grapevine, TX, May 2009.

${ }^{21}$ Liu, L., Friedmann, P. P., Kim, I., and Bernstein, D. S., "Rotor Performance Enhancement and Vibration Reduction in Presence of Dynamic Stall Using Actively Controlled Flaps," Journal of the American Helicopter Society, Vol. 53, No. 4, October 2008, pp. 338-350.

${ }^{22}$ Glaz, B., Friedmann, P. P., and Liu, L., "Vibration Reduction and Performance Enhancement of Helicopter Rotors Using an Active/Passive Approach," Proceedings of the 49th AIAA/ASME/ASCE/AHS/ACS Structures, Structural Dynamics and Materials Conference, Schaumburg, IL, April 2008, AIAA Paper No. 2008-2178.

${ }^{23}$ Glaz, B., Friedmann, P. P., Liu, L., Kumar, D., and Cesnik, C. E. S., "The AVINOR Aeroelastic Simulation Code and Its Application to Reduced Vibration Composite Rotor Blade Design," Proceedings of the 50th AIAA/ASME/ASCE/AHS/ACS Structures, Structural Dynamics and Materials Conference, Palm Springs, CA, May 2009, AIAA Paper No. $2009-2601$.

${ }^{24}$ Brenter, K., A Computer Program Incorporating Realistic Blade Motions and Advanced Acoustic Formulation, NASA Technical Memorandum, Vol. 877211986.

${ }^{25}$ Roget, B. and Chopra, I., "Closed-Loop Test of a Rotor with Individually Controlled Trailing-Edge Flaps for Vibration Reduction," Journal of the American Helicopter Society, Vol. 55, No. 1, Jan. 2010, pp. 1-12.

${ }^{26}$ Maughmer, M. D., Lesieutre, G. L., and Kinzel, M. P., "Miniature Trailing-Edge Effectors for Rotorcraft Performance Enhancement," Proceedings of the 61st Annual American Helicopter Society Forum, Grapevine, TX, June 2005. 
${ }^{27}$ Kinzel, M. P., Maughmer, M. D., Lesieutre, G. L., and Duque, E. P. N., "Numerical Investigation of Miniature TrailingEdge Effectors on Static and Oscillating Airfoils," Proceedings of the 43rd AIAA Aerospace Sciences Meeting and Exhibit, Reno, NV, Jan 2005, AIAA Paper No. 2005-1039.

${ }^{28}$ Kinzel, M. P., Maughmer, M. D., and Lesieutre, G. L., "Miniature Trailing-Edge Effectors for Rotorcraft Performance Enhancement," Journal of the American Helicopter Society, Vol. 52, No. 2, April 2007, pp. 146-158.

${ }^{29}$ Kinzel, M. P., Maughmer, M. D., and Duque, E. P. N., "Numerical Investigation on the Aerodynamics of Oscillating Airfoils with Deployable Gurney Flaps," AIAA Journal, Vol. 48, No. 7, July 2010, pp. 1457-1469.

${ }^{30}$ Min, B. Y., Sankar, L., and Bauchau, O. A., "A CFD-CSD Coupled Analysis of Hart II Rotor Vibration Reduction Using Gurney Flaps," Proceedings of the 66th American Helicopter Society Annual Forum, Phoenix, AZ, May 11-13 2010.

${ }^{31}$ Liu, L., Padthe, A. K., and Friedmann, P. P., "A Computational Study of Microflaps with Application to Vibration Reduction in Helicopter Rotors," Proceedings of the 50th AIAA/ASME/ASCE/AHS/ACS Structures, Structural Dynamics and Materials Conference, Palm Springs, CA, April 2009.

${ }^{32}$ Padthe, A. K., Liu, L., and Friedmann, P. P., "A Comprehensive Study of Active Microflaps for Vibration Reduction in Rotorcraft," Proceedings of the 66th American Helicopter Society Annual Forum, Phoenix, AZ, May 2010.

${ }^{33}$ Padthe, A. K., Liu, L., and Friedmann, P. P., "Vibration Reduction in Rotorcraft Using Active Microflaps," Proceedings of the 36th European Rotorcraft Forum, Paris, France, September 7-9 2010.

${ }^{34}$ Rogers, K. L., Airplane Math Modeling Methods for Actively Control Design, AGARD-CP-228, August 1977.

${ }^{35}$ Edwards, J. H., "Application of Laplace Transform Methods to Airfoil Motion and Stability Calculations," Proceedings of the 20th Structures, Structural Dynamics and Materials Conference, St. Louis, MO, April 1979, AIAA Paper No. $1979-772$.

${ }^{36}$ Karpel, M., Design for Active and Passive Flutter Suppression and Gust Alleviation, NASA Contractor Report 3492, Nov. 1981.

${ }^{37}$ Vepa, R., Finite State Modeling of Aeroelastic Systems, NASA Contractor Report 2779, 1977.

${ }^{38}$ Myrtle, T. F. and Friedmann, P. P., "Application of a New Compressible Time Domain Aerodynamic Model to Vibration Reduction in Helicopters Using an Actively Controlled Flap," Journal of the American Helicopter Society, Vol. 46, No. 1, Jan. 2001, pp. 32-43.

${ }^{39}$ Liu, L., Friedmann, P. P., and Padthe, A. K., "Comparison of Approximate Time Domain Aerodynamics for Flapped Airfoils with CFD Based Results with Applications," Proceedings of the AHS Specialists' Conference on Aeromechanics, San Francisco, CA, January 2008.

${ }^{40}$ Liu, L., Friedmann, P. P., and Padthe, A. K., "An Approximate Unsteady Aerodynamic Model for Flapped Airfoils Including Improved Drag Predictions," Proceedings of the 34th European Rotorcraft Forum, Liverpool, UK, September 2008.

${ }^{41}$ Peroomian, O., Chakravarthy, S., Palaniswamy, S., and Goldberg, U., "Convergence Acceleration for Unified-Grid Formulation Using Preconditioned Implicit Relaxation," AIAA Paper 98-0116, Reno, NV, January 1998.

${ }^{42}$ Peroomian, O., Chakravarthy, S., and Goldberg, U., "A "Grid-Transparent" Methodology for CFD," AIAA Paper 970724, Reno, NV, January 1997.

${ }^{43}$ Allwine, D. A., Strahler, J. A., Lawrence, D. A., Jenkins, J. E., and Myatt, J. H., "Nonlinear Modeling of Unsteady Aerodynamics at High Angle of Attack," Proceedings of the AIAA Atmospheric Flight Mechanics Conference and Exhibit, Providence, RI, Aug 2004.

${ }^{44}$ Padthe, A. K., Liu, L., and Friedmann, P. P., "A CFD-Based Nonlinear Reduced-Order Aerodynamic Model for Comprehensive Simulation of Rotorcraft with Active Microflaps," Proceedings of the 65th American Helicopter Society Annual Forum, Grapevine, TX, May 2009.

${ }^{45}$ Boor, C. D., A Practical Guide to Splines, Springer-Verlag, 2001.

${ }^{46}$ Kahaner, D., Moler, C., and Nash, S., Numerical Methods and Software, Prentice-Hall, 1989.

${ }^{47}$ Press, W. H., Flannery, B. P., Teukolsky, S. A., and Vetterling, W. T., Numerical Recipes in FORTRAN 77, Cambridge University Press, 1992.

${ }^{48}$ Liu, L., Padthe, A. K., Friedmann, P. P., Quon, E., and Smith, M. J., "Unsteady Aerodynamics of Flapped Airfoils and Rotors Using CFD and Approximate Methods," Proceedings of the 65th American Helicopter Society Annual Forum, Grapevine, TX, May 2009.

${ }^{49}$ de Terlizzi, M. and Friedmann, P. P., "Active Control of BVI Induced Vibrations Using a Refined Aerodynamic Model and Experimental Correlation," American Helicopter Society 55th Annual Forum Proceedings, Montreal, Canada, May 25-27 1999, pp. 599-615.

${ }^{50}$ Patt, D., Liu, L., and Friedmann, P. P., "Rotorcraft Vibration Reduction and Noise Prediction Using a Unified Aeroelastic Response Simulation," Journal of the American Helicopter Society, Vol. 50, No. 1, Jan. 2005, pp. 95-106.

${ }^{51}$ Abbott, I. H. and Doenhoff, A. E. V., Theory of Wing Sections, chap. 4, Dover Publications, Inc., 1959, pp. 75-79.

${ }^{52}$ Patt, D., Liu, L., Chandrasekar, J., Bernstein, D. S., and Friedmann, P. P., "Higher-Harmonic-Control Algorithm for Helicopter Vibration Reduction Revisited," Journal of Guidance, Control, and Dynamics, Vol. 28, No. 5, September-October 2005, pp. 918-930.

${ }^{53}$ Cribbs, R. and Friedmann, P. P., "Actuator Saturation and Its influence on Vibration Reduction by Actively Controlled Flaps," AIAA Paper No. 2001-146\%. Proceedings of the 42nd AIAA/ASME/ASCE/AHS/ACS Structures, Structural Dynamics and Materials Conference, Seattle, WA, April 2001.

${ }^{54}$ Splettstoesser, W., Kube, R., Wagner, W., Seelhorst, U., Boutier, A., Micheli, F., Mercker, E., and Pengel, K., "Key Results From a Higher Harmonic Control Aeroacoustic Rotor Test (HART)," Journal of the American Helicopter Society, Vol. 42, No. 1, Jan. 1997, pp. 58-78. 